\title{
Green Tribology for the Sustainable Engineering of the Future
}

\author{
Mitjan Kalin* - Marko Polajnar - Maja Kus - Franc Majdič \\ University of Ljubljana, Faculty of Mechanical Engineering, Slovenia
}

Environmental awareness and especially the legislation that requires the reduction of polluting emissions are strong driving forces toward more sustainable engineering and greener solutions in the design, use and overall life span of machinery. However, providing novel concepts that will exclude non-environmentally adapted, but over many years developed and optimized solutions, is not an easy task. It clearly requires time if the same level of technical performance is to be maintained. Green tribology is one of the fields that has been closely involved in these actives in the past two decades. The research and use of tribology science and technology toward green and sustainable engineering include natural material usage, lower energy consumption, reducing natural oil resources, reducing pollution and emissions, fewer maintenance requirements and thus reduced machinery-investment cycles. This report is not an attempt to cover all the existing concepts, attempts or literature available in the field, but mainly those efforts that our group has been working on over the past 20 years, which mainly includes novel green-lubrication concepts that come from exploring and exploiting surface engineering through the use of diamond-like-carbon (DLC) coatings.

Keywords: green lubrication, DLC coatings, low SAPS oils, biodegradable oils, nanoparticles, boundary slip, ionic liquids, water lubrication

Highlights

- Green tribology is closely involved and required field in a sustainable engineering of the future.

- New and innovative contacts with lower wear and friction and with lubrication concepts at a more sustainable and environmental level need to be developed.

- Green tribology is a newly developing and challenging field of modifying and innovating new tribology concepts, but having as a benchmark high-performance contacts that did not required to fully consider the sustainable engineering needs and were developed over many decades. This is thus a challenging task.

- We present some conceptual issues with green tribology in this work.

- Eight combinatorial green tribology concepts, involving DLC coatings and various lubrication technologies are presented with some results and potential for implementation.

\section{O INTRODUCTION}

\subsection{The Need for Green Tribology in Sustainable Engineering}

It is becoming very clear, with overwhelming evidence from researchers worldwide, that the use of fossil-based fuels is the key source of climate change. The consequences of this are rising temperatures, which are more than obvious, as well as rising sea levels and many catastrophic situations due to extreme weather. Therefore, we need to act immediately to reduce these energy-consumption levels as well as pollution in many forms, such as limitations on $\mathrm{CO}_{2}$ and particle emissions in internal combustion engines, by, for example, EURO regulations, [1] (Fig. 1). What is more, through the UN Framework Convention on Climate Change (UNFCCC) [2], the Kyoto protocol [3] and the 2015 United Nations Climate Change Conference [4] held in Paris in 2015, 170 countries are now legally bound to reduce the amounts of energy they use from conventional fuel resources. In order to meet these obligations, lowering friction and reducing wear will play a critical role, Fig. 2.

If we consider all of the energy consumed on the planet, from industry to the home, and from the oceans to the skies, a massive $25 \%$ is taken up by friction [5] and [6]. The 2015 figures from the International Energy Agency [7] suggest these frictional losses amount to a massive $5000 \mathrm{kWh}$ for every person on earth. Moreover, every device or machine has a limited life-time due to the material damage caused by the wear of moving contacting surfaces. This wear leads to problems such as poor production quality, vibrations, noise and malfunctions.

This is expensive in terms of both the energy costs and the financial costs associated with the wearrelated replacement of parts [8] and [9], machinery and vehicles that leads to increased demands for more production, and thus more energy consumption and so more pollution. Indeed, $2 \%$ to $3 \%$ of gross domestic product (GDP) in industrialized regions such as Europe is spent on wear-related replacements [10] and [11], which gives us an idea of how much energy is involved in this. Advances in tribology - the science 


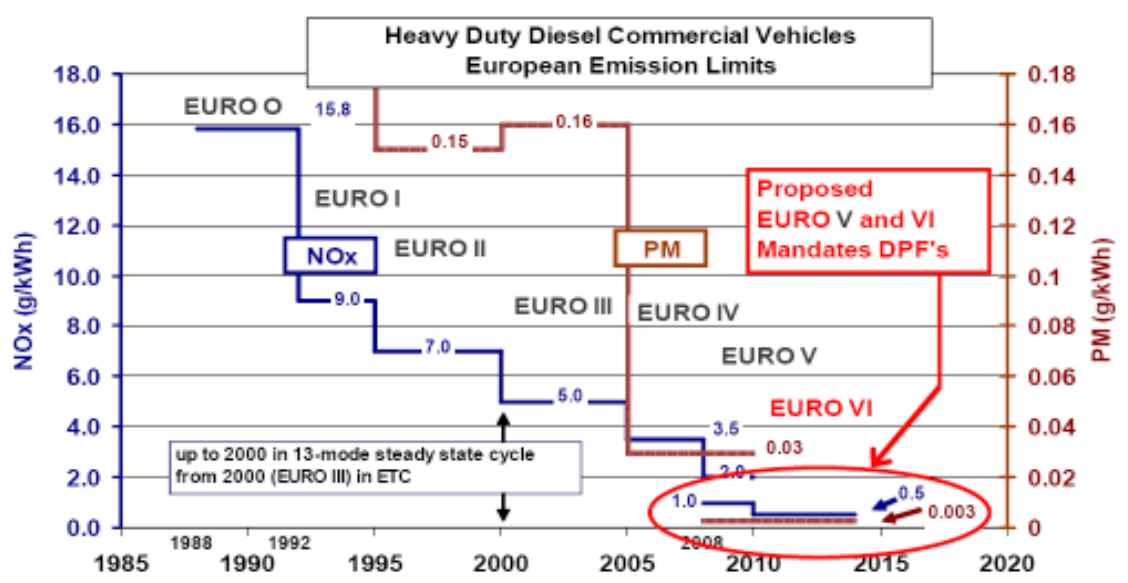

Fig. 1. Demands of the novel EURO standards for the emission limits of internal combustion engines

and technology of friction, wear and the lubrication of contacting surfaces in relative motion - are crucial for reducing friction and thereby saving energy and reducing climate change.

Lubricants consisting of a base oil and additives are the obvious and the most common means to reduce friction and wear, by interacting with materials and surface coatings to develop wear-protective and lowfriction interface layers. However, the constituents of most effective lubricants are made from sulfur, phosphorus, zinc and other environmentally polluting elements. Here, national and international legislations have already placed severe constraints on the use of and demands for abandoning several of the most effective lubricant additives [12]. It has been estimated that if new green-lubrication technologies are not developed by 2021, the performance of a massive range of machinery will deteriorate, with serious technical and economic consequences [13].

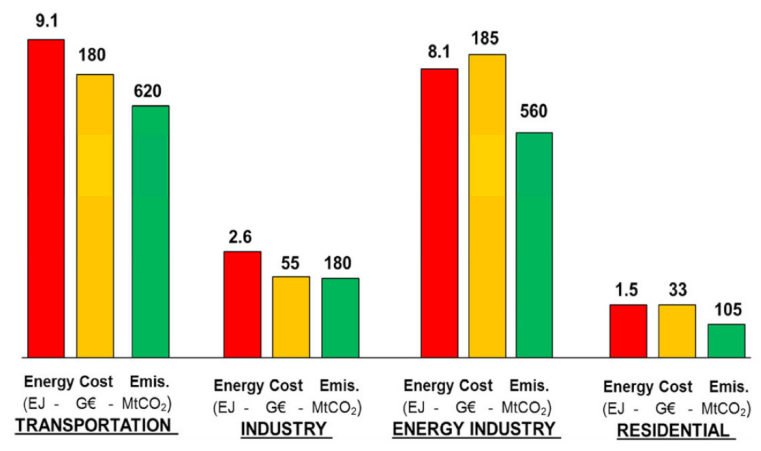

Fig. 2. Potential annual energy, cost and $\mathrm{CO}_{2}$ emission savings globally after 8 years of intensive advanced tribology implementation $\left(1 \mathrm{EJ}=1018 \mathrm{~J}, \mathrm{G} €=\right.$ Euro $\mathrm{GDP}, \mathrm{MtCO}_{2}=$ million tons of $\left.\mathrm{CO}_{2}\right)$ [6]
Thus, the challenge for green tribology is to reduce both friction and wear and improve lubrication in a sustainable way. However, in today's extremely advanced state of technology it is not sufficient to merely design a new, green lubricant or additive, adapt novel bulk materials or produce advanced low-friction surface coatings. The compatibility between these various components is complex and current solutions have taken years of development and optimization. If any new engineering contact is to result in substantially lower friction and wear, it needs to be sensitively tailored into an innovative combination of substrate, coatings, lubricant and additive, adapted to an optimized joint performance with low friction and wear, typically through the formation of particular $\mathrm{nm}$-scale interface layers in these contacts.

\subsection{The Challenges in Green Tribology}

Green tribology was only defined as a scientific term in 2009 [14]. When we look at the content in publications dealing with green tribology, it turns out that they mainly describe what green-tribology research means [15], present some individual green-tribology goals or individual green-tribology principles, which are not entirely generalized [15], and describe the areas in which green tribology can be achieved [16] and [17], and in which applications it can be employed [16]. From an engineer's perspective, as someone who tends to employ or design a green tribological system, the term green tribology has tended to be used in the context of three principal thematics: biodegradable lubricants, biomimetic surfaces and green technologies such as wind turbines or tidal electric generators, etc. [18] and [19]. However, in this 
way green tribology is frequently thought of in terms of isolated, or even hypothetical, solutions without a clear and feasible industrial scope, thus lacking a wideranging applicability. The general concepts of how to tackle the needs of green and sustainable tribological solutions are not widely explored and such contact systems are not well defined. However, several studies have already demonstrated that original, innovative, breakthrough green concepts are possible in tribology. The following section describes some of the current commonly discussed green-tribology solutions and their challenges.

For example, original, innovative approaches include chemical-based interactions with organic, environmentally adapted chemistry [20] and [21], and especially biodegradable lubricants (Fig. 3). To date, green tribology has been broadly considered as the use of biodegradable oils, lessening our impact on the environment [22] and [23]. However, biodegradable oils have already been used to reduce pollution for decades. Many studies [17] and [24], products [25] and [26] and legislation requirements [27] and [28] have already been developed. Accordingly, biodegradable lubrication is not a "new" concept of green tribology itself. However, it certainly represents one of the pillars that can be further developed in combination with different contacting materials that will reduce pollution overall. So, thinking in terms of the entire contacting system - a full-contact engineering approach - may further alter the green impact of biodegradable lubricants. However, there are many more potential options that need to be explored and evaluated.

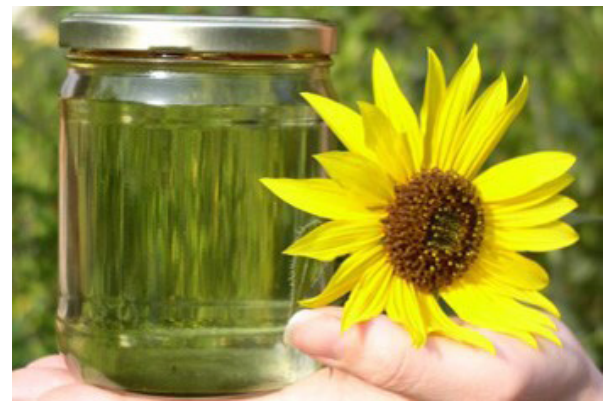

Fig. 3. Biodegradable lubricants from sunflowers have excellent lubricating properties at moderate temperatures, and are noticeably less harmful for the environment than fossil-based lubricants

Furthermore, biomimetics and the behaviors of natural surfaces, such as a shark's skin or a water strider's hydrophobic microhairs [15], [29] and [30] that exhibit low friction and serve as examples for mimicking them in the technical world, also show the potential for reducing friction and energy consumption; however, it still has an extremely limited or no role in green tribology or sustainable engineering. They are applied in only a few specific products, thus their impacts on energy consumption, polluting emissions, and resource depletion are very limited or non-existent. One such example is Speedo's famous Fastskin swimsuit (Fig. 4), inspired by the varying texture of a shark's skin that increased the efficiency of swimming, but it has no obvious impact on sustainable living. Therefore, green tribology needs to re-focus from these limited areas to the engineering areas where society can benefit the most.

The first idea of the sharkskin concept, with the specific design of the skin features, implies a reduction of the turbulence at the solid-liquid boundary layer and smoother and easier flow of the fluid over the surface. This idea can be roughly related to attempts to modify the lubricated friction via surface texturing [31]. There are many examples of friction and energyconsumption reduction through surface texturing due to optimized fluid flow, which is now becoming an affordable and used technology in many applications. This concept is certainly green; however, in such a generally defined result, all tribological solutions can be considered as green, because all tribology studies aim to reduce friction and/or wear. Therefore, future original and innovative green solutions that will employ new surface topographies and functionalities will have to synergistically integrate other concepts to become novel, system-generic, green technologies.

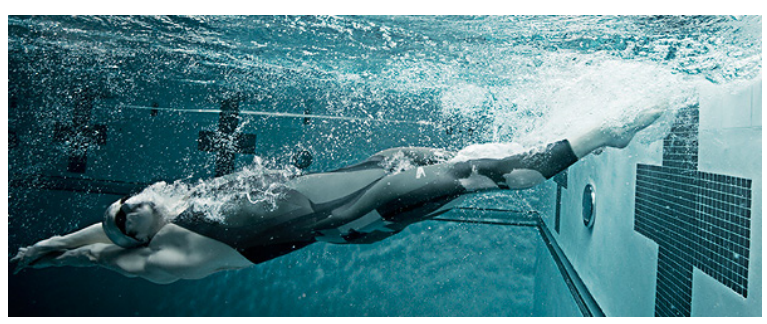

Fig. 4. Speedo's Fastskin swimsuit inspired by the texture of a shark's skin

Finally, green tribology should be closely related to many fast-developing green applications, such as producing green energy [15] and [23]. Namely, wind turbines (Fig. 5), wave- and tide-energy devices, are clearly bringing more green and sustainable engineering, similar to electrical and hybrid cars. However, it turns out that very often these systems do not employ any inherently green tribology concepts during their construction, operation, maintenance, or 
decommissioning. This means they are only giving the impression of true, green innovation, whereas in fact the device itself may be devoid of green lubrication, and might have been built without any thought to resource depletion. From this it is very clear that generic green-tribology contacts and systems must be developed with proper green-engineering concepts in order to have a measurable green impact, which should span the product's whole life cycle. We must remember, it is only green if it is green from start to finish, "from cradle to grave".

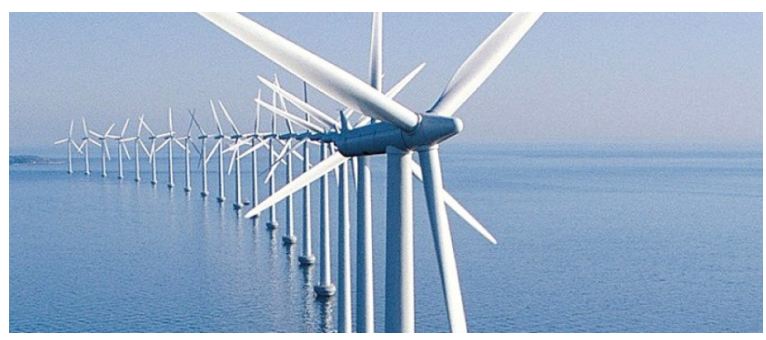

Fig. 5. Wind turbines in an offshore field; is this system designed in a truly green way?

\section{SOME GREEN-TRIBOLOGY CONCEPTS ASSOCIATED WITH DLC COATING ENGINEERING}

Our studies include a number of green-tribology concepts that have been investigated over the past 20 years. These include, in all cases, diamond-like carbon (DLC) coatings, Fig. 6. DLC coatings are an amorphous material consisting mainly of carbon atoms in the $\mathrm{sp}^{2}$ or $\mathrm{sp}^{3}$ hybridization, typically with some hydrogen content, with many doping strategies being employed to tailor their properties.

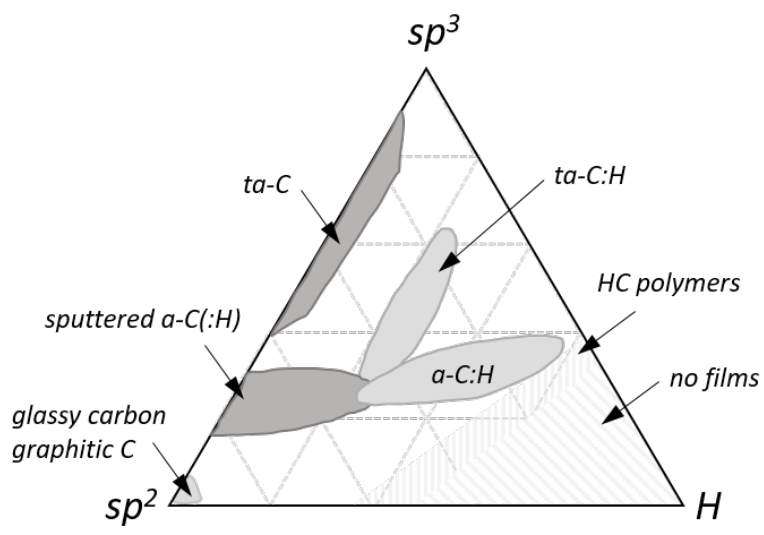

Fig. 6. Ternary phase diagram of the amorphous carbonhydrogen system

In the search for the best surface solutions under lubricated conditions, DLC coatings are becoming very attractive due to their inherent low-wear and low-friction properties [32] to [35]. However, the key benefit, but also a challenge with DLC coatings and so with their lubrication, is their low reactivity [33] and [36] to [38]. They exhibit very low adhesion, which gives them a low-friction property, but on the other hand this means that their interactions with lubricants are weak, and difficult to control or predict. So, DLC coatings give problems and opportunities at the same time, and thus a great potential for innovative lubrication solutions - including green tribology. So far these coatings have already been implemented in many components in the automotive industry, such as gears, cam shafts, and piston rings (Fig. 7).

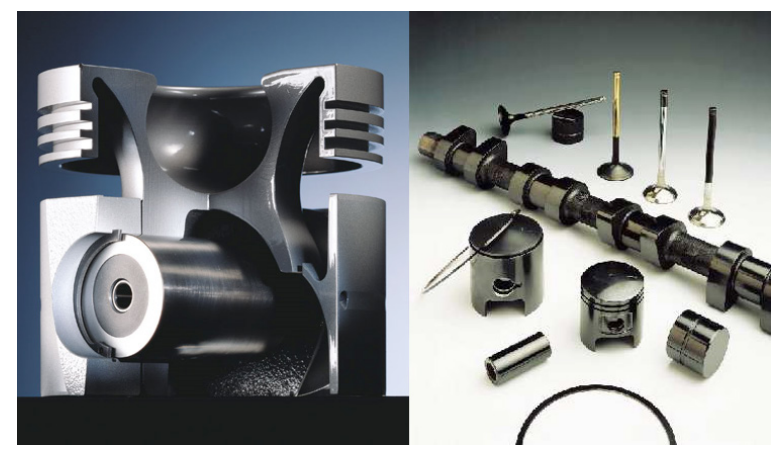

Fig. 7. Some of typical components in automotive applications that are often coated with DLC coatings

\subsection{Biodegradable Oils}

The most obvious way to reduce the environmental danger and harm associated with conventional lubricating oils was to employ biodegradable oils. In the early days, the DLC reactivity toward oils was still very much under question and many controversial results were reported because of a lack of a detailed methodology and the novelty of the field of DLC lubrication. However, the idea of employing biodegradable oils with DLC was tempting. We showed that biodegradable lubricants actually perform very well with DLC coatings. Moreover, due to the large number of polar functional groups, biodegradable oils are highly polar and so more reactive than regular mineral or synthetic oils. This has shown to be a very effective lubrication mechanism for bio-degradable oils with DLC coatings [39], Fig. 8. This beneficial effect of green lubrication was also proved in several applications, such as gears [40], grinding machines [41] and hydraulics [42]. 


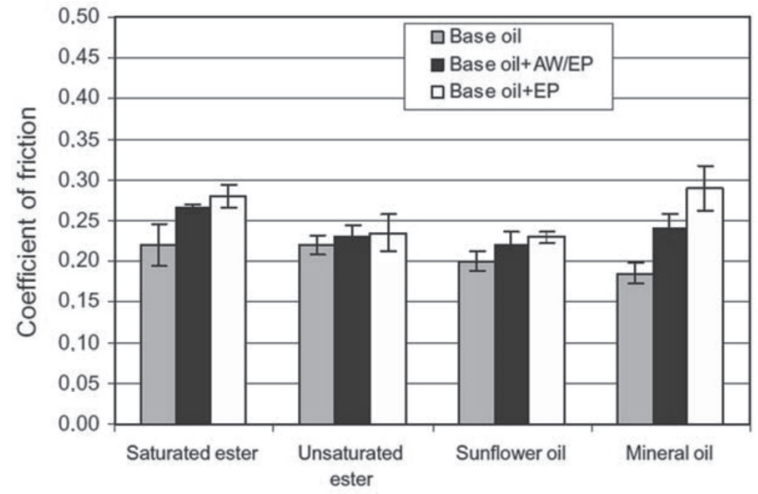

Fig. 8. Coefficient of friction in $D L C / D L C$ contacts for mineral and different bio-degradable oils [39]

\subsection{Low-SAPS Oils}

In the past 20 years many chemically based interactions between different additives and DLC coatings were studied. Initially, strong extremepressure (EP) additives or the most effective types of anti-wear (AW) additives were investigated to first find the clear interactions between the additives and the DLC [36], [37] and [43] to [45], which were at that time still questioned. Nevertheless, direct chemical evidence of the interactions between additives and DLC surfaces were obtained using different surfacesensitive techniques [45] to [49]. Indeed, these interactions were weaker than those with steel and

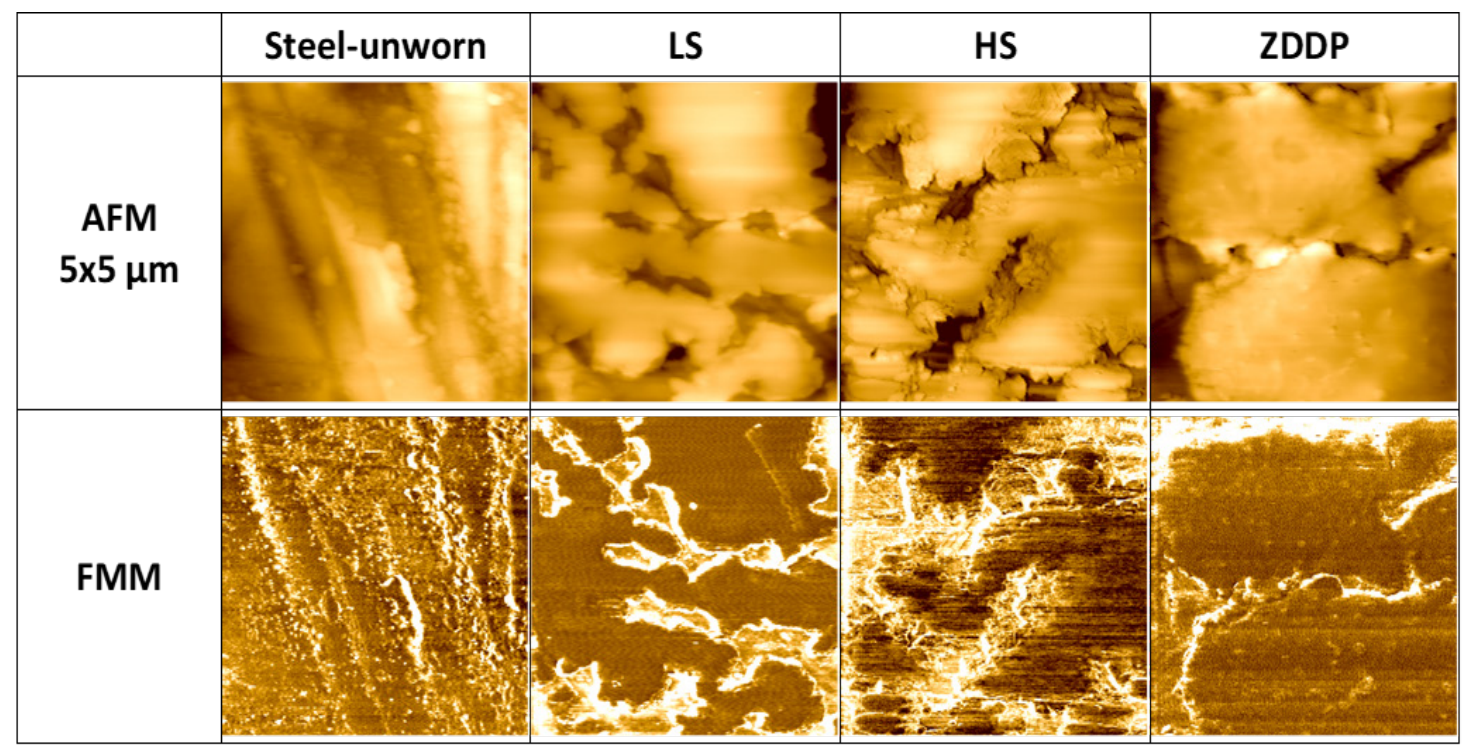

Fig. 9. Friction-force modulation (FFM) and AFM topography image; for FFM the darker area represents a lower stiffness and the brighter area a higher stiffness; LS stands for low SAPS, HS for high SAPS and ZDDP for this additive in base oil [53]

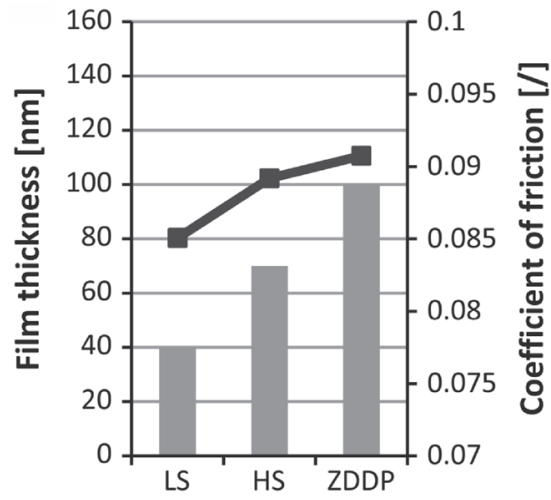

Fig. 10. Correlation between film thickness and macroscopic coefficient of friction on Si-DLC surfaces [53] (Note: Columns represent the film nano-thickness, line represent the friction.) occurred to a lesser extent. Moreover, the positive effect of DLC doping with different elements was proposed and shown empirically with several coatings [37] as well as by chemical analyses [46] and [50]. Accordingly, evidence of the chemical reactivity of DLC coatings with relatively strong additives (mainly sulfur-containing, as well as phosphorus-containing) was presented in the literature. In view of these and many other studies it became obvious that very strong interactions between the DLC and the additives would hardly be possible with contemporary additives. The requirement for greener lubrication was then a clear push to developing even stronger DLC-tailored additives, which may not be the best route for DLC lubrication solutions, and especially green sustainable 


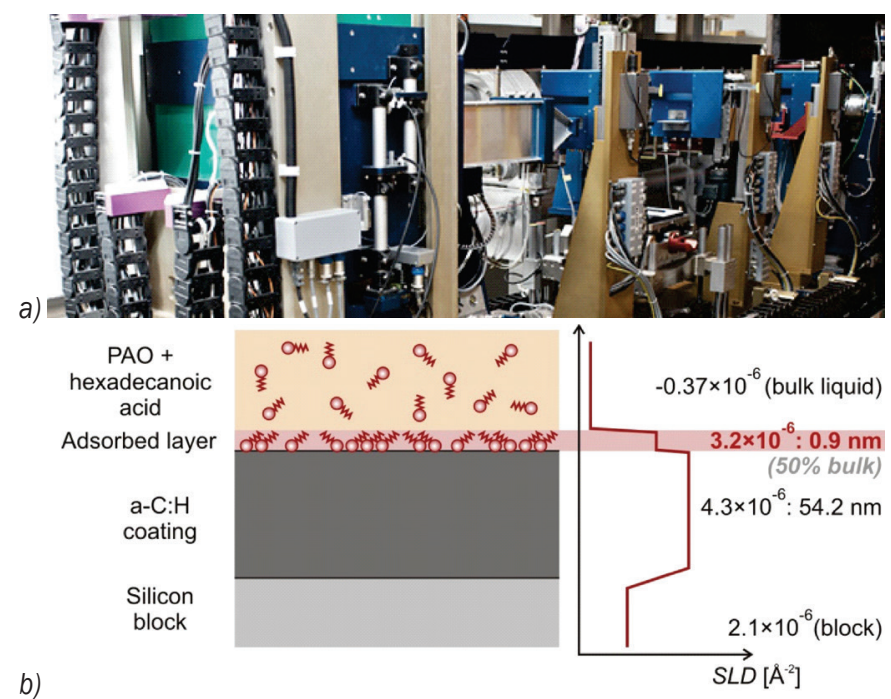

Fig. 11. a) Photograph of a neutron-reflectivity final stage set-up; and b) a model of adsorbed boundary film (SLD is scattering length density) based on the results of neutron reflectometry from [58]

engineering. Accordingly, many studies have focused on low-sulphated ash, phosphorus and sulfur (SAPS) oils and their interactions with DLC [51] to [54]. These studies showed that even low-SAPS oils can effectively protect the surfaces and reduce the friction. Moreover, in many cases the friction was lower with low-SAPS than with high-SAPS oils or with the wellknown Zinc dialkyldithiophosphate (ZDDP)-based oils [53] and [54]. These observations were associated with the mechanical properties of the films that were revealed by using an atomic force microscope in the force-modulation mode and shown in terms of the mechanical properties of two different film areas, Fig. 9. Detailed analyses of the tribofilms from low-SAPS oils revealed the low film thickness of the films, which was nevertheless sufficient to reduce the wear and friction. In fact, in contrast to steel, the DLC-coated surfaces resulted in lower friction if the tribofilms were thinner [53] and [54], Fig. 10.

\subsection{Simple Mild Organic Additives}

The above-mentioned findings led to further thoughts on the effect of mild additives, with low coverage or low thickness, which may be sufficient to reduce wear and friction. Several detailed studies of the adsorption ability of these additives were performed using atomic-force microscope (AFM) and neutron reflectometry [55] to [59]. The latter technique is very sensitive to a determination of the sub-nanoscale boundary layers of the additives, Fig. 11. These studies included detailed, nano-scale analyses of the adsorbed layers from alcohols and fatty acids, as well as their density and thickness, Fig. 11b. Indeed, it was found that alcohols and fatty acids do form adsorbed layers on DLC coatings, Fig. 12. These are not complete mono-layers, but may only partially

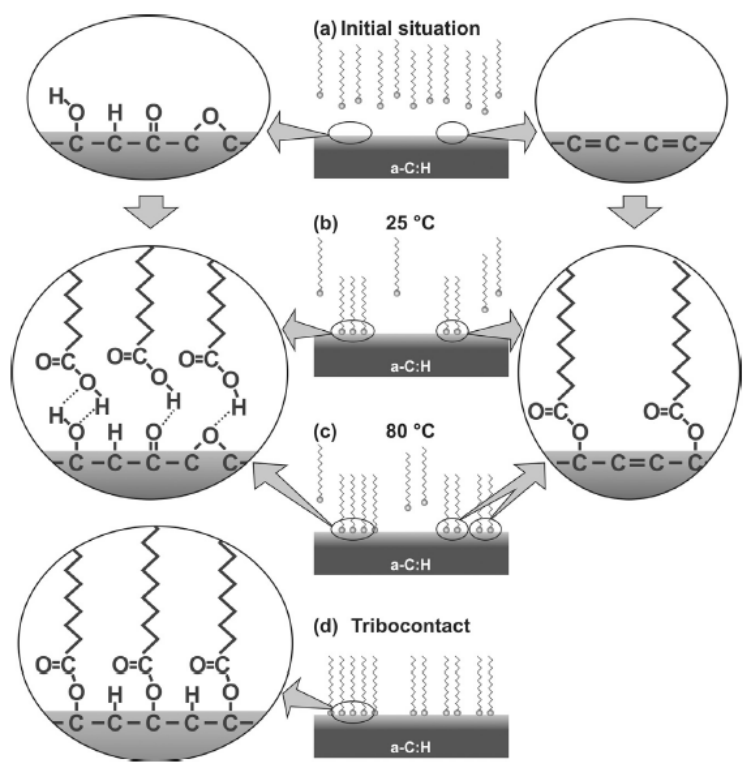

Fig. 12. Schematic representation of the physical and chemical adsorption of a fatty acid onto a DLC surface for: a) the initial situation where the surface is partially covered with oxides and hydroxides (due to ambient air and moisture); b) at $25{ }^{\circ} \mathrm{C}$ where hydrogen bonds are formed; c) at $80^{\circ} \mathrm{C}$ that promotes the adsorption significantly; and d) in the tribocontact where rubbing induces chemisorption [55] 
cover the surfaces, since densities of only $50 \%$ were measured and the layer thicknesses were less than 1 $\mathrm{nm}$. This is in agreement with molecular-dynamics and quantum-chemistry investigations that showed very similar behavior [60]. A model for the interaction of simple alcohols and fatty acids was proposed, with a clear conclusion that fatty acids are more effective than alcohols [56], but friction can be clearly reduced with such mild, organic additives on DLC coatings [55] and [57].

\subsection{Base Oil Molecular Structure and Rheology Effects}

One more phenomenon was revealed during a study of various oils in DLC lubrication. Namely, that the lubricated friction of a very smooth DLC is typically larger than non-lubricated. The reason lies in the fact that low-adhesion DLC coatings, when very smooth, which further surpresses the friction from asperity deformation or scratching, results in very low friction values. However, when adding a lubricant, viscous friction is actually added to the contacts. Accordingly, lubricant layers with a longer molecule or a higher viscosity have higher cohesion energies and thus stronger molecular forces. Such lubricant layers should be more difficult to shear and/or penetrate through for the asperities; therefore, they should separate the surfaces at the asperity contacts better. However, completely different behavior related to the increased friction with increased chain lengths and viscosity was noted for the DLC surfaces. Namely, compared to the non-lubricated conditions, additional energy was needed to move and penetrate through the lubricant molecules in the contact under high pressure, a)
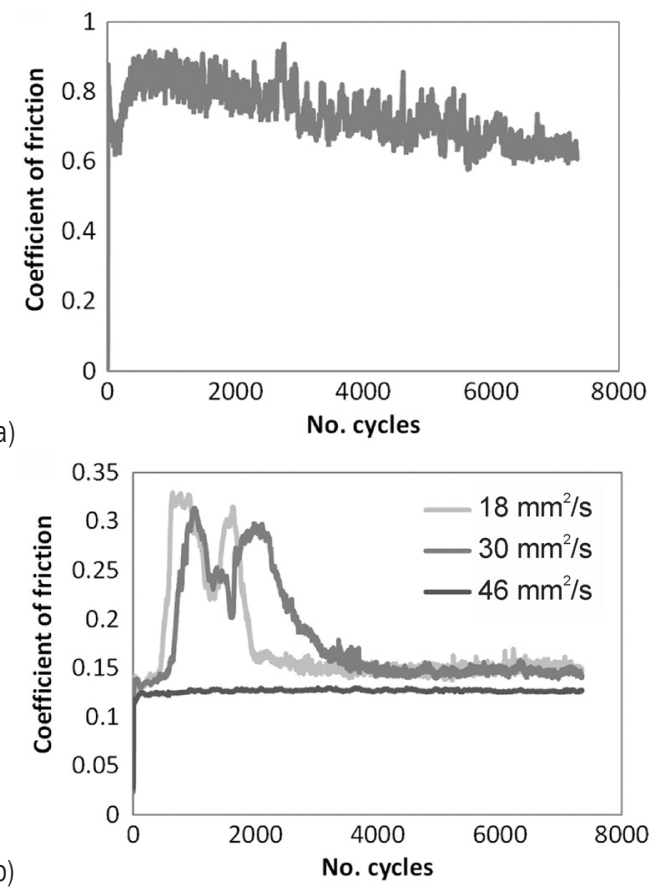

b)

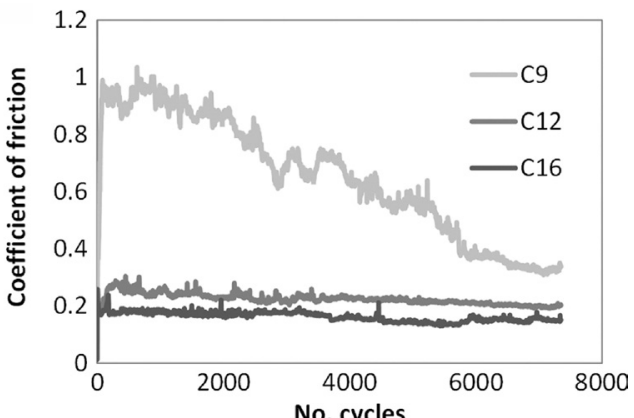

c)

Fig. 13.
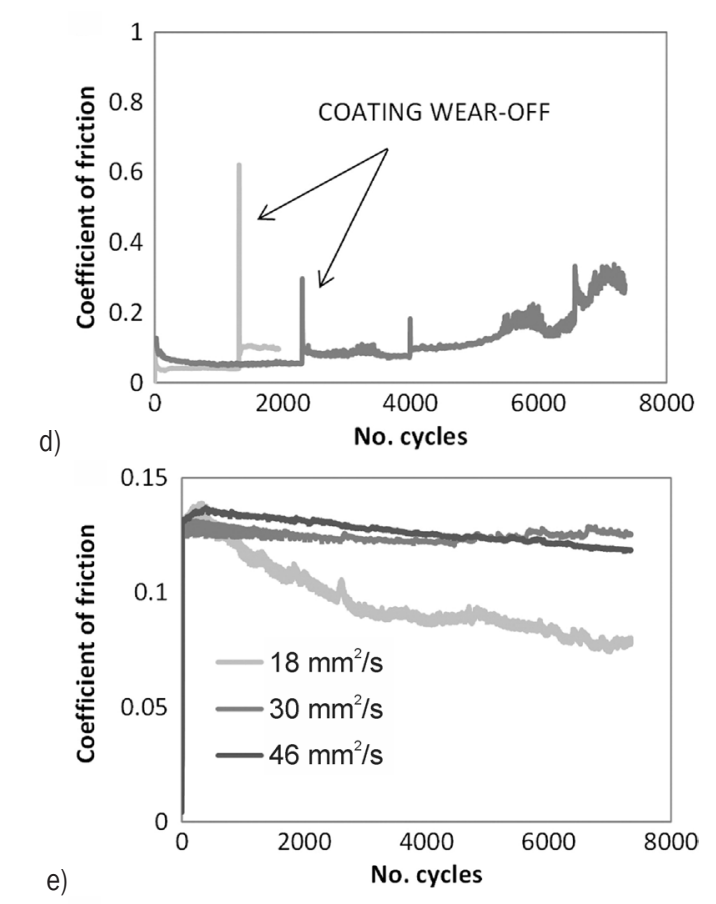

e)

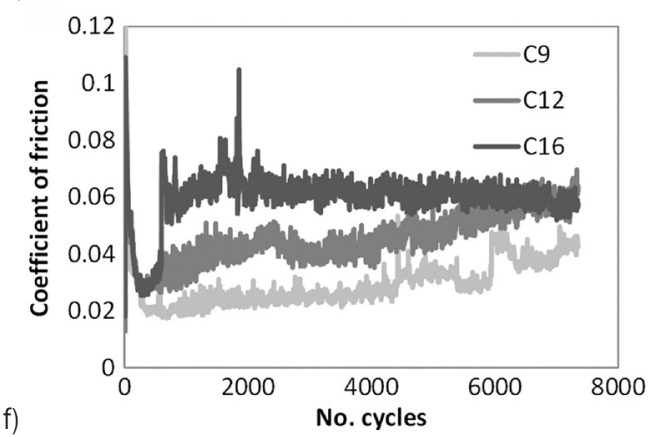


which were adsorbed on the contacting surfaces, and so the friction increased (compare Figs. 13d, e and f). This is because when the material has inherently lowfriction properties under non-lubricated conditions, as is the case with the DLC coatings, [61] to [63], the additional force needed to shear the lubricant layers in the contact is higher than the reduction of adhesion or deformation, which are the two main sources of friction in the boundary lubrication of conventional metal surfaces, Fig. 14. The higher the molecular chain length or viscosity, the higher the cohesive energy of the layer, and thus more energy is required to break or shear it, and thus the friction is higher. Our results clearly confirm these relations, both for the poly-alpha olefin (PAO) oils and the pure alkanes [64]. In contrast, in the case of steel, the oil significantly reduces the adhesive interactions and thus the tangential forces required to break the metallic covalent bonds, which otherwise occur easily under non-lubricated conditions, [65], (compare Figs. $13 \mathrm{a}, \mathrm{b}$ and $\mathrm{c})$.
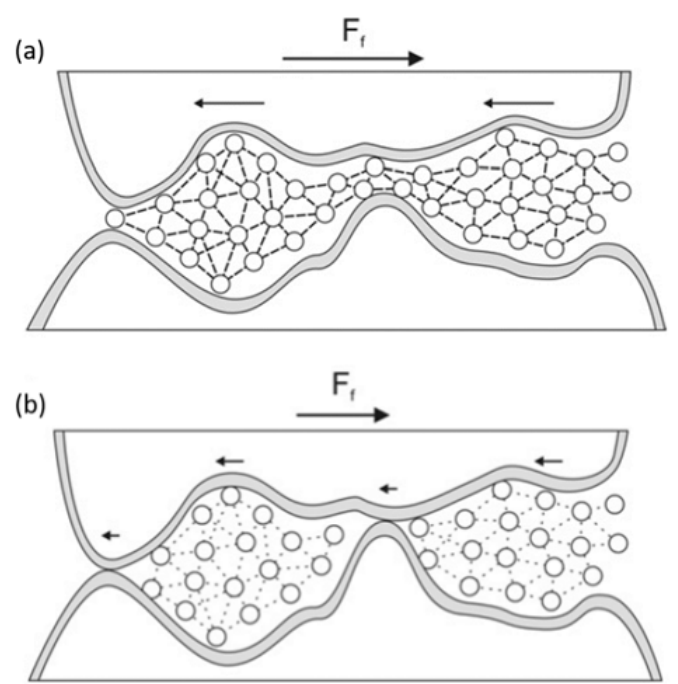

Fig. 14. Schematic of a DLC/DLC contact lubricated with a) high-shear and (b) low-shear lubricant, representing its highand low-cohesion strengths, respectively [64]

It is thus very important to note that DLC provides both low wear and friction also with the base oils only. Accordingly, although strong reactive additives were found to improve the wear behavior of the DLC, they may not be required for DLC-coated systems, especially since sometimes they also increase the friction, and the wear of the coatings is already low compared to steel surfaces. From this point of view, milder additives, such as low- or no-SAPS additives, may be sufficient to protect even the most heavily loaded contacts, when coated with DLC, while being able to maintain other non-coated surfaces in the system under satisfactory tribological conditions.

\subsection{Nanoparticles}

Since it has become clear that DLC coatings are not adequately active toward chemical-based additives, other concepts that are predominantly physical based seem very welcome as potential lubrication solutions for DLC green technology. Self-lubricating nanoparticles are thus an interesting lubricating concept to be explored from various points of view. The idea of nanoparticle-assisted lubrication was proposed as a promising concept some time ago. However, despite the numerous types of nanoparticles that have already been tested and some that have already been used in practical applications, several tribological mechanisms and the relevant influential parameters under different contact conditions have yet to be determined.

Following the advances in conventional solid lubrication and the established theory of the transfer films [66] and [67], research has focused on the tribology of graphite-like nanostructures, i.e., C60 fullerenes [68] and [69], carbon nanotubes [70] and [71] and carbon nano-onions [72] and [73]. In lubricated conditions, however, the nanoparticles used were mainly fullerene-like structures of IF- $\mathrm{MoS}_{2}$ (Fig. 15) and IF-WS 2 , where it was revealed that these inorganic nanoparticles perform very effectively as additives in lubrication fluids [74] to [77].

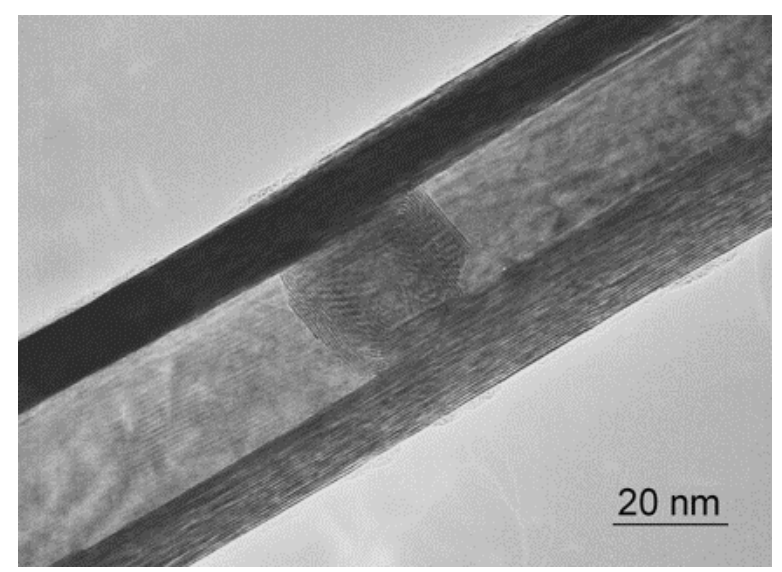

Fig. 15. TEM image of the $\mathrm{MoS}_{2}$ nanotube, i.e., "mama-tube" (Courtesy dr. Maja Remškar, Jožef Stefan Institute, Ljubljana, Slovenia)

The proposed low-friction mechanisms of the nanoparticles are similar to their macro-scale structures, i.e., based on low-shear basal planes 


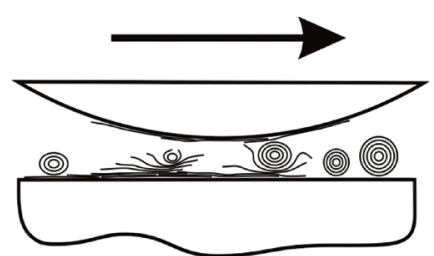

Exfoliation and formation of low-shear film

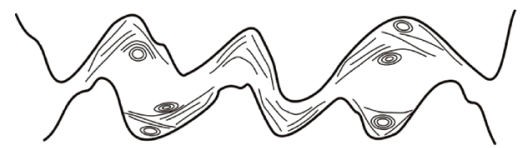

Nanoparticle deposition in valleys of surfaces: i. to reduce real contact pressure, ii. acting as a reservoir
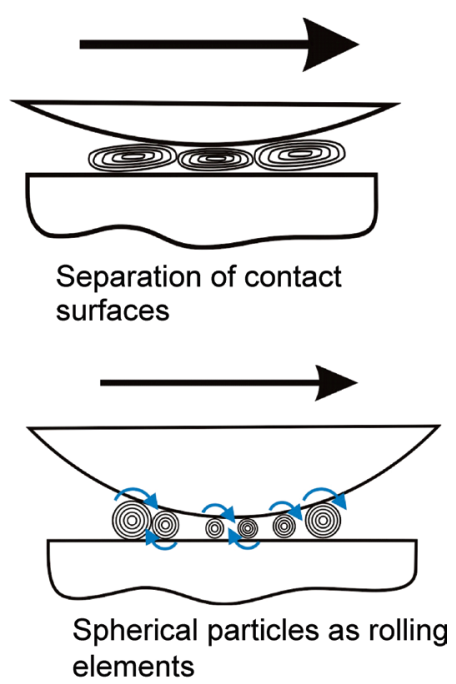

Fig. 16. Lubrication using nanoparticles, based on physical mechanisms, without any SAPS

of layered materials, such as $\mathrm{MoS}_{2}, \mathrm{WS}_{2}$, and/or graphite. There have also been other mechanisms proposed (Fig. 16), most frequently the rolling of the nanoparticles, and this mechanism again does not include any chemical reactions with elements and compounds associated with environmental emissions. It should be stressed that $\mathrm{MoS}_{2}$, which is one of the best-known solid lubricants, is also a very chemically stable compound, which means it is not likely to contribute to emissions. Accordingly, it seems that nanoparticles, once placed in a lubricated mechanical system, can form protective nano-sheets at the surface and provide low friction and wear with a limited environmental impact, representing the potential for novel green-lubrication technologies.

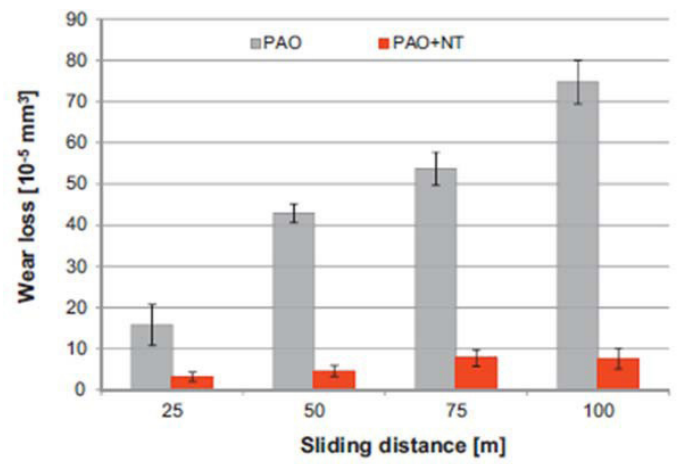

Fig. 17. Wear loss of steel balls in a contact lubricated with pure base oil (PAO) and base oil with 5 wt.\% $\mathrm{MoS}_{2}$ nanotubes (PAO+NT) depending on the sliding distance [77]

However, the nanoparticle-lubrication mechanisms are not yet fully agreed, and the research still tackles some fundamental problems related to the dispersion, agglomeration/aggregation and sedimentation of nanoparticles in oils. For this reason, available studies and results with nanoparticles in oils are still mainly in combination with steel or other metal surfaces, and these results suggest huge improvements in friction and wear performance, such as, for example, those in our own work [78] using $\mathrm{MoS}_{2}$ nanotubes in PAO oils, Fig. 17.

Accordingly, solid-lubricating layered structures, such as $\mathrm{MoS}_{2}$ and $\mathrm{WS}_{2}$ nanoparticles, which are effective through a physically based lubrication mechanism (Fig. 16), can simultaneously provide a solution for the two above-discussed problems. Firstly, they can act as physical-based additives in lubricants for poorly reactive surfaces such as DLC coatings and similar non-conventional materials that cannot react effectively with today's chemically based additives. Secondly, since inorganic nanoparticles of $\mathrm{MoS}_{2}$ and $\mathrm{WS}_{2}$ are synthesized in closed forms with highly inert basal planes [79], they are chemically non-reactive and do not result in harmful emissions. So, their second advantage is in reducing the emissions and consequently - at least partially - solving the problem of the necessary elimination of high-SAPS additives and thus providing the possibility for a novel, greenlubrication technology.

In addition to the common nanoparticles of $\mathrm{MoS}_{2}$, $\mathrm{WS}_{2}$ and carbon nano tube (CNT), graphene is another very promising material with many positive examples and potential. There has been a huge global interest in and study of graphene properties; however, it is surprising that there are very few studies on macro- 
scale tribology dealing with graphene as an additive to lubricants [80] to [83]. Our resent work has shown the great potential of graphene as a green oil additive, having much better tribological performance than conventional graphite or CNT [84]. This is another novel result from a series of nanoparticle studies that we made in the past decade, to look at the potential of graphene as an oil additive.

\subsection{Oil-Surface Boundary Slip}

Another concept for green lubrication can be realized through tailored physical-chemical interactions at the solid-liquid interfaces that induce slip at the lubricated contacting surfaces, Fig. 18. This solid-liquid slip is a well-known phenomenon and can be observed in nature, as the lotus-leaf effect, or in everyday life, as the slip of an oil droplet on a polytetrafluoroethylene (PTFE)-coated pan, Fig. 19.
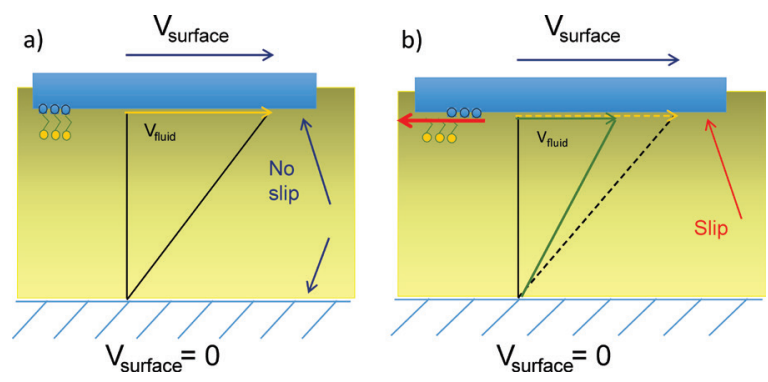

Fig. 18. Solid-liquid interface: a) without boundary slip; and b) with boundary-slip conditions

Recently, we have shown that, based on modified surface energies for tailored lubricants to reduce wetting behavior, friction can be significantly reduced, by up to $50 \%$, and lubrication design can be modified based on these parameters. Several papers describe this new concept in lubrication design [85], the effect of various materials and wetting properties [86], and the contact configuration [87], Fig. 20.

The DLC coating was used as a model material, since DLC coatings are known to have a lower surface energy than steel and poorer wetting. Fig. 21 shows the friction reduction in the elasto-hydrodynamic lubrication (EHL) regime only due to the use of surfaces where at least one surface possesses poorer wetting and/or surface energy compared to steel. Similar results supporting this concept were also reported in some other studies [88] and [89].

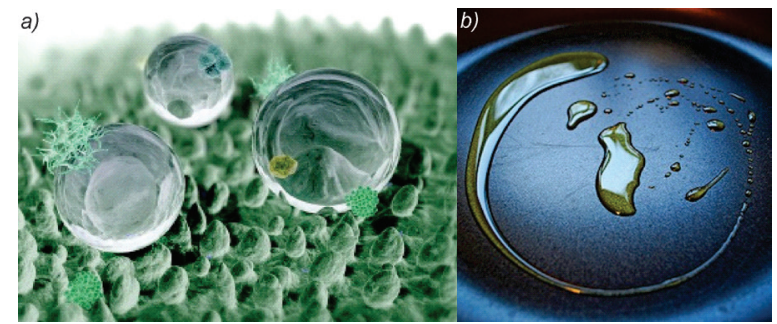

Fig. 19. Two examples of solid-liquid slip: a) the lotus-leaf effect; and b) an oil droplet in a PTFE-coated pan

We have further verified these suggestions and the concept by purposely using several different DLC coatings, having a variety of different surface characteristics, and the same conclusion was always confirmed [86] and [87]: DLC surfaces result in less friction than steel in the EHL regime, and also during the transition from mixed to EHL. Moreover, when only one such surface is in contact, the friction is higher than in the case of two such surfaces, but it is lower than with both steel surfaces (steel/steel) in contact (see Fig. 21). The results in the boundary regime appear the same, but further tests need to be conducted to confirm the behavior in this regime. (a)

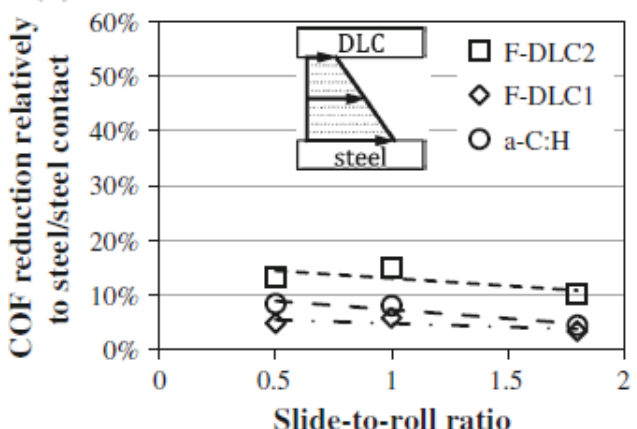

(b)

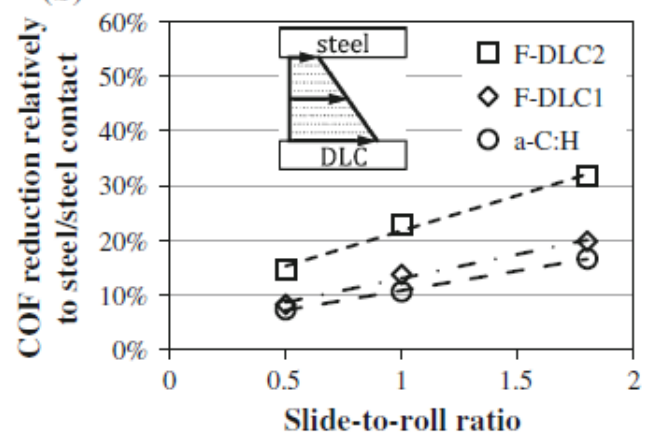

Fig. 20. Relative decrease in the coefficient of friction in the case of mixed steel/DLC contacts compared to a steel/steel contact for DLC on: a) slow; and b) fast surface [87] 


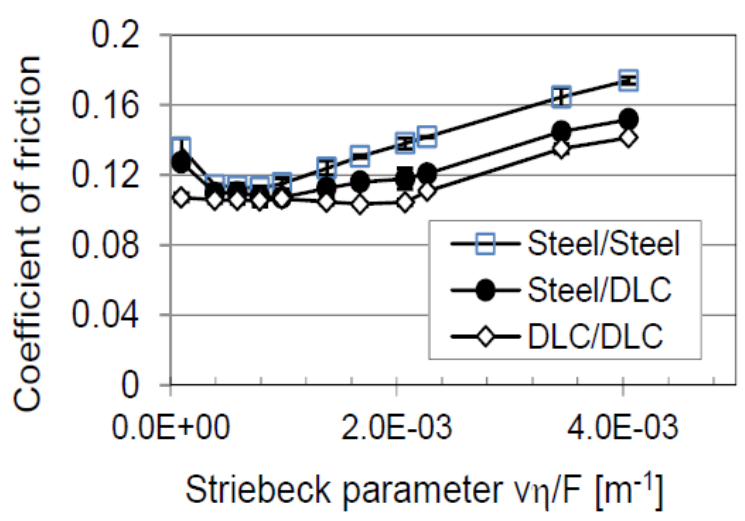

Fig. 21. Friction reduction using one or two DLC surfaces with a lower surface energy and wetting [85]

Although the concept of solid-liquid slip is well-known and was previously already observed to reduce friction drag under different circumstances, primarily theoretically, using various model materials or experiments on the nano scale [90] to [94], this was not comprehensively investigated on the macro scale with engineering materials and lubricants, with the exception of a few studies [85] to [89] and [93]. Accordingly, it turns out that although the relevance of solid-liquid interface properties is well-accepted, a model that correlates these parameters and friction does not yet exist, and only indirect, empirical correlations to establish these parameters are available today [85].

Considering the above findings on wetting effects, one can reasonably assume that if the wetting conditions change the elasto-hydrodynamic (EHD) friction due to the use of low-surface-energy DLC coatings, similar effects can be obtained by modifying the wetting with adsorbed additive layers. However, there is almost no information about whether, and how, the additives change the wetting and the role that the temperature plays. Moreover, if the additives can affect the wetting properties, instead of hard surface coatings such as DLC, this would have a huge beneficial economic effect due to the lower cost and easier application method than the surface coatings on the most commonly used steel surfaces. Our latest investigations showed that additives indeed modify the wetting, both at room [95] and elevated temperatures. As seen in Fig. 22, advancing contact angles that were varied systematically for several molecular structures of simple organic additives, change a lot, indicating the strong potential for the additives to be tailored for a specific wetting and slip property. Moreover, it
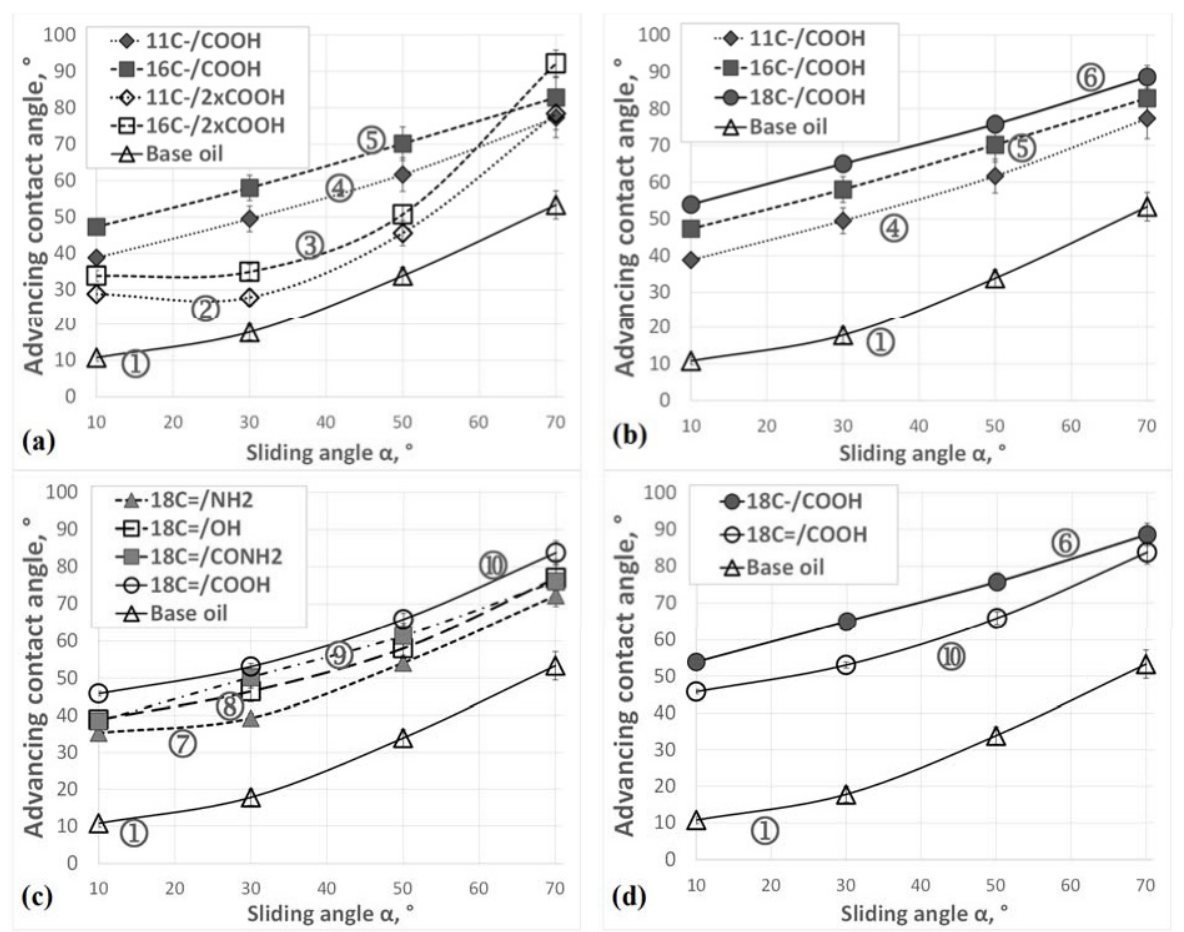

Fig. 22. Influence of a) different number of $\mathrm{COOH}$ groups; b) different chain length of the additive; c) different polarity of functional groups; and d) saturation of additive on advancing contact angle for steel with and without additives [95] (Note: nine polar molecules were used as additives, having different chain length, polar head-group, saturation and number of polar head-groups.) 


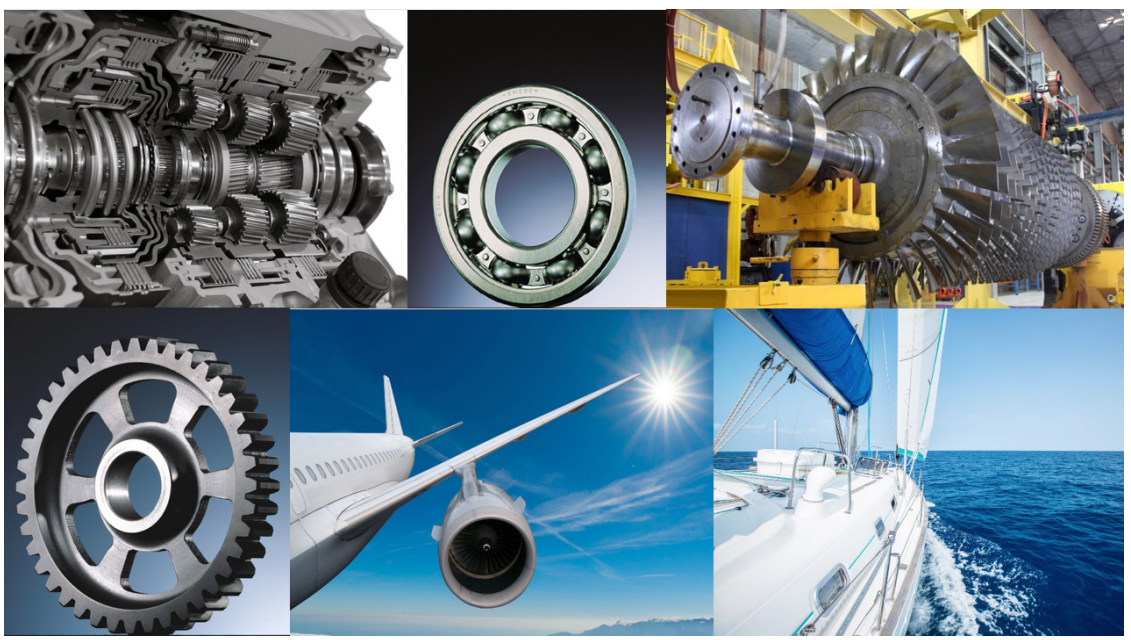

Fig. 23. Some potential applications where wetting effects and solid-liquid slip concept could be implemented to reduce the friction in a green and sustainable way

was found that these adsorbed layers also noticeably reduce the EHD friction.

The concept of slip tailored by wetting properties is thus a promising concept for enormous savings in terms of energy consumption for all applications with solid-liquid interfaces where the fluid resistance represents a major part of the drag force and friction, Fig. 23.

\subsection{Ionic Liquids}

One of the latest attempts to develop green and efficient lubricated contacts is to use DLC coatings with ionic liquids, which are salts that are liquid at temperatures below $100{ }^{\circ} \mathrm{C}$. The reason lies in the fact that ionic liquids are very reactive molecules, which may strongly interact with the DLC, especially when doped, as well as being green in nature. Namely, ionic liquids are salts composed of positively charged cations and negatively charged anions [96], Fig. 24. They exhibit some unique properties, which make them good candidates for lubrication additives, for example, low vapor pressure, high thermal stability, electrochemical range, non-flammability and being benign to the environment [97] to [99]. So far, there are no literature reports on whether such lubricated contacts can perform satisfactorily and whether ionic liquids can indeed be a potential additive for DLC. This study is on going, but some of the results suggest an extremely low coefficient of friction under selected conditions, thus giving hopes for niche applications, where such a green-lubrication technology could be introduced.<smiles>CCCCP(C)(C)(CCCC)CCCC</smiles><smiles>COP(=O)([O-])OC</smiles>

Fig. 24. Molecular structure of a phosphate-based ionic liquid (Tributylmethylphosphonium dimethylphosphate $\left(\mathrm{C}_{15} \mathrm{H}_{36} \mathrm{O}_{4} \mathrm{P}_{2}\right)$ ) with positive and negative ionic parts

\subsection{Water Lubrication}

Finally, water has been generating huge interest over the years as the ultimate environmentally acceptable fluid, especially if used without additives. Environmental awareness and its protection are becoming increasingly important when it comes to lubrication in engineering applications, in particular in open-air environments, where oil spilling directly pollutes nature, such as in forests, marine, mining, agriculture, etc. In this view, water lubrication represents a green-lubrication technology that could replace conventional oil lubrication [100]. However, due to its low viscosity and very poor lubrication with respect to conventional steels, water is not suitable for the lubrication of machines in its present form. Thus, tribological engineering needs to be introduced in the contacting surfaces and to modify the conventional contacts.

In the past, extremely successful cases were shown where water was used as a lubricant in ceramic contacts, with applications including a water pump with ceramic seals (Fig. 25), or tap-water valves. 
Namely, silicon nitride or silicon carbide provide super-low friction of 0.002 and 0.0035 when sliding in water [100] to [103].

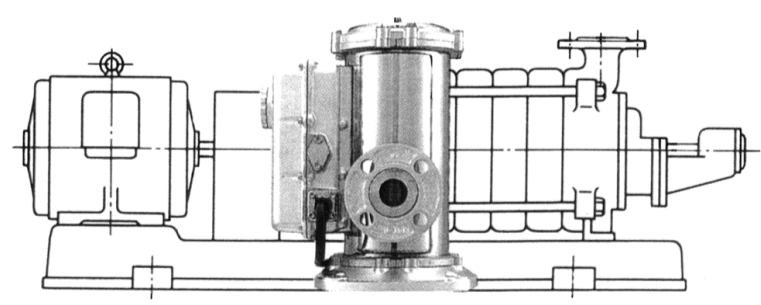

Fig. 25. Water pump with 5-imes-reduced volume due to the implementation of SiC seals (Courtesy prof. K. Kato, K. Adachi, Tohoku University, Sendai, Japan)

However, the strong effect of water $\mathrm{pH}$, zetapotential, ionic composition and so geographical dependence was recognized [104] to [107], Fig. 26.
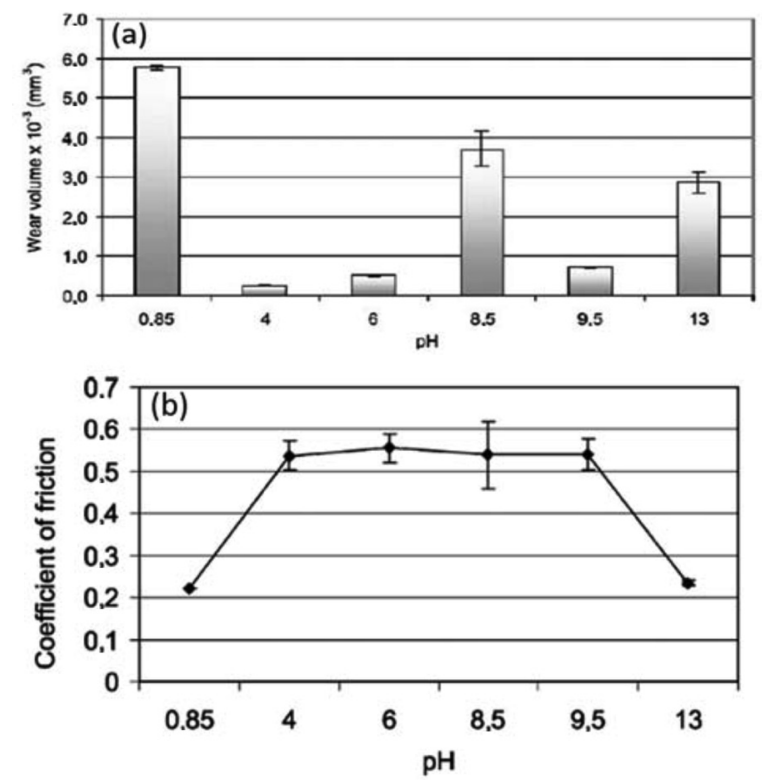

Fig. 26. Effect of water $\mathrm{pH}$ on: a) wear volume of alumina pins; and (b) steady-state coefficient of friction [104]

For the broader use of water in engineering applications, however, steel surfaces are of interest. Accordingly, surface-engineering techniques for steel substrates need to be introduced to overcome the limitations of water lubrication on a broader scale. DLC [108] is one possible coating for improving the tribological behavior under water-lubricated conditions [109] and [110]. Namely, water-lubricated DLC has proved to be a tribologically successful combination [111] to [113]. Detailed mechanistic analyses regarding DLC in water were conducted by Ohana [114] to [117]. DLC under water-lubricated conditions results in very low wear [114] and moreover, friction below 0.1 when DLC is sliding in water against steel is typically observed [109].

We have also shown earlier that surface engineering with DLC coatings in water can notably improve the performance of a proportional $4 / 3$ waterhydraulic valve [118], Fig. 27. In this work, both a model tribological study and a full-scale test with a hydraulic valve's life-testing, corresponding to 6 months of operation at 8 hours per day, was performed. In life-testing, the DLC-coated components remained within an acceptable $1 \%$ leakage, compared to 20 $\%$ leakage in steel contacts, while model tribological tests showed up to 6-times lower friction.

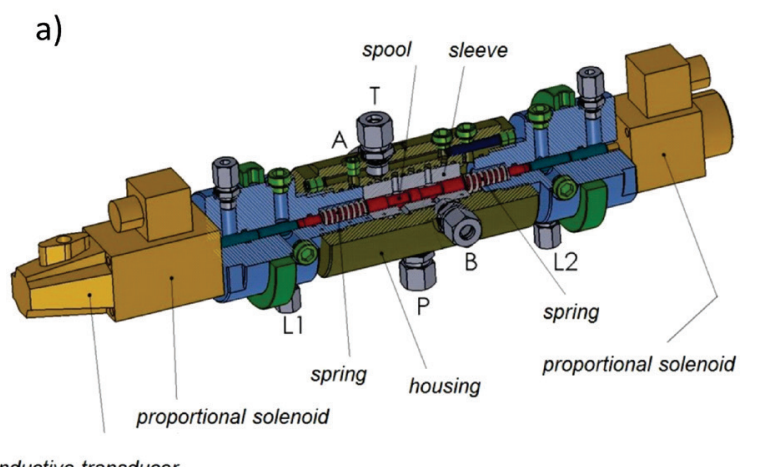

b)

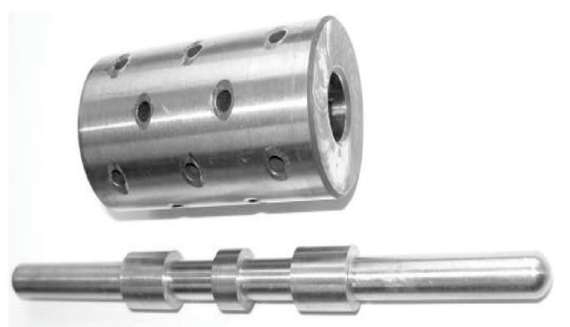

Fig. 27. a) Schematic of a $4 / 3$ water-hydraulic valve operating with a DLC coating in water; and b) spool and sleeve samples that were tested in 4/3 water-hydraulic valve [118]

The above-mentioned application and experiments were performed at low contact pressures, but our very recent work focused on a high-contactpressure application. Namely, to a low-speed, but high-torque, orbital hydraulic motor, which normally operates under oil-lubricated conditions [119]. Such a hydraulic motor is a highly loaded mechanical component that converts hydraulic energy into the rotational motion of the shaft. A combination of an appropriate geometry of the mechanical parts, the holes in the valve plate and the pressure differences in the lobes ensures that the rotational speed of the shaft is up to $25 \mathrm{~min}^{-1}$ and that the torque is up to $1000 \mathrm{Nm}$. A problem with the hydraulic motor is its 
low overall efficiency, which is closely related to the friction and wear [119]. However, this work showed that with an appropriate modification of the contacts, with the appropriate roughness, DLC coatings can greatly improve the contact performance, and so reduce the friction and wear. In fact, friction in steel/ DLC contacts with water, even in such highly loaded contacts, is lower than steel/steel in oil. Moreover, the application of DLC to several contacts in an orbital hydraulic motor (Fig. 28) allowed the motor to run, which was not the case with only the steel parts. Although an efficiency of only $23 \%$ was achieved [120], the highly loaded orbital hydraulic motor was able to operate in water-lubricated conditions. In spite of much more work being required, this points the way toward green water-lubrication even in the most heavily loaded contacts in machinery used in natural environments.
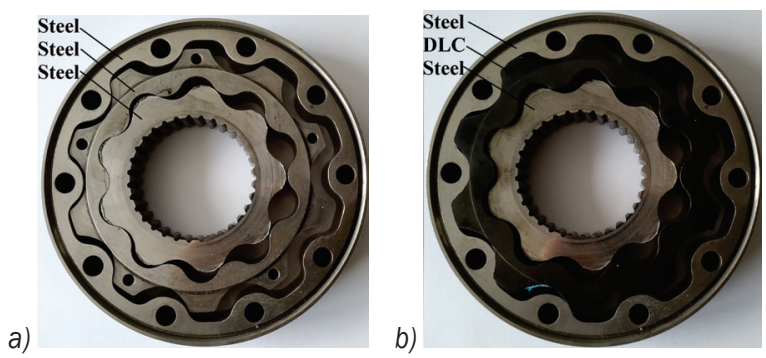

Fig. 28. Mechanical parts of hydraulic motor: a) original steel design and; b) modified design employing a DLC coating [120]

\section{DISCUSSION AND CONCLUSIONS}

Creating a sustainable engineering future will require a more comprehensive understanding of green tribology as a concept that encompasses the complete engineering life-cycle and the skills, knowledge and expertise to provide environmentally sustainable solutions and more general green tribological contacts and solutions, applicable in many engineering mechanical systems. To ensure that green tribology becomes central to engineering design, researchers will need information and knowledge covering these topics in the public domain. In fact, this is also the focus of a recent European-wide research activity to develop general and green tribology concepts within the framework of the GreenTRIBOS initiative [121]. The GreenTRIBOS project aims to develop several green-tribology contacts and systems, complete designs including materials, coatings, lubricants and surfaces that will be green in their essence. This is just one systematic attempt and many more systematic and comprehensive approaches from many groups world- wide is needed to achieve the challenging goals of green and sustainable engineering.

In this work we have shown some of current issues related to the question, what green tribology actually means and how to tackle it. Although there are many more individual studies, approaches and definitely success stories, a lot more can be achieved in the future. It is not the intention of this work to cover all these, to make a fully and complete review study, so the authors apologize for not being able to cover every aspect. Namely, this report is made on the occasion of the 100-year anniversary of the University of Ljubljana (1919-2019) and mechanical engineering studies, which have been part of the university since then. The major emphasis was thus on the work of the group of current authors in this field. Nevertheless, we believe this is a relevant collection and summary of many possible approaches that we already attempted or even pioneered in the field. These include DLC coatings due to their specific and truly fantastic properties, enabling so many various functionalities.

We believe DLC coatings can also serve as a model approach, where not only green lubricants, but also the surfaces, with all their many different properties, can contribute to a novel functionality. In this work we show as many as eight different green-lubrication concepts due to such a propertycombinatorial approach. We can call it an inter- and multi-disciplinary approach as well. Namely, it is clear that novel design concepts, including novel greenlubrication concepts, will need to combine ideas and knowledge out of the box. By doing so, unexpected successes can be anticipated. We should not forget that current successful lubrication technologies are based on century-long studies and research. Accordingly, we look forward to many more successful greenlubrication solutions in the coming years.

\section{ACKNOWLEDGEMENT}

The authors wish to thank A. Neville and A. Morina (University of Leeds), N. Emami and R. Larsson (Lulea University of Technology) and A. Cavaleiro and B. Trindade (Coimbra University) for their contribution and discussions in developing new ideas in green-tribology research within GreenTRIBOS project [121]. The authors also wish to thank all the contributors to various studies and their parts presented in this work, in particular J. Kogovšek, S. Akbari, E. Oblak, R. Simič, L. Bartolome, F. Kopač and E. Strmčnik (when performing research, appointed at University of Ljubljana). The authors also acknowledge the financial support from the 
Slovenian Research Agency ARRS (research core funding No. P2-0231).

\section{REFERENCES}

[1] Blaž, J., Zupan, S., Ambrož, M. (2019). Study on the eligibility of introducing hybrid-drive buses into the public passenger transport. Strojniški vestnik - Journal of Mechanical Engineering, vol. 65, no. 1, p. 553-558, D0l:10.5545/svjme.2018.5637.

[2] United Nations Framework Convention on Climate Change (2015). From: http://unfccc.int/2860.php, accessed on 2015-12-14.

[3] Kyoto Protocol (2015). From: https://en.wikipedia.org/wiki/ Kyoto_Protocol, accessed on 2019-09-16.

[4] United Nations Climate Change Conference (2015). From: https://en.wikipedia.org/wiki/2015_United_Nations_ Climate_Change_Conference, accessed on 2019-09-16.

[5] Dake, L.S., Russell, J.A., Debrodt, D.C. (1986). A review of DOE ECUT tribology surveys. Journal of Tribology, vol. 108, no. 4, p. 497-501, Dol:10.1115/1.3261252.

[6] Holmberg, K., Erdemir, A. (2017). Influence of tribology on global energy consumption costs and emissions. Friction, vol. 5, no. 3, p. 263-284, DOl:10.1007/s40544-017-0183-5.

[7] KeyWord Statistic (2015). From: https://www.iea.org/ publications/freepublications/publication/KeyWorld_ Statistics_2015.pdf, accessed on 2019-09-16.

[8] Luo, K., Wang, Y., Liu, H., Dular, M., Chen, J., Zhang, Z. (2019). Effect of coating thickness on a solid-liquid two-phase flow centrifugal pump under water medium. Strojniški vestnik Journal of Mechanical Engineering, vol. 65, no. 4, p. 251-262, DOI:10.5545/sv-jme.2018.5865.

[9] Zhang, J., Ma, P., Gan, S., Hu, X., Wang, S. (2019). A novel approach for identifying gas cavitation in oil jet pumps for lubrication systems. Strojniški vestnik - Journal of Mechanical Engineering, vol. 65, no. 2, p. 113-122, D0l:10.5545/svjme.2018.5656.

[10] Oak Ridge National Laboratory (USA) (2015). From: http:// web.ornl/sci/physical_sciences directorate/mst/SurfacePM/ tribology.html, accessed on 2019-09-16.

[11] Jost, H.P. (1966). Lubrication (Tribology) - A Report on the Present Position and Industry's Needs. Department of Education and Science, H. M. Stationary Office, London.

[12] Euro VI Emission standards (2015). From: https:// en.wikipedia.org/wiki/European_emission_standards, accessed on 2019-09-16.

[13] Euro Emission Standards Explained (2015). From: https:// www.carkeys.co.uk/guides/euro-emission-standardsexplained, accessed on 2019-09-16.

[14] Jost, H.P. (2009). Green Tribology - A Footprint Where Economies and Environment Meet. 4th World Tribology Congress, Kyoto.

[15] Nosonovsky, M., Bhushan, B. (2010). Towards the "Green Tribology": Biomimetic surfaces, biodegradable lubrication, and renewable energy. Proceedings of STLE/ASME International Joint Tribology Conference, San Francisco, p. 435-437, DOI:10.1115/ijtc2010-41157.
[16] Bartz, W.J. (2006). Ecotribology: Environmentally acceptable tribological practices. Tribology International, vol. 39, no. 8, p. 728-733, D0l:10.1016/j.triboint.2005.07.002.

[17] Pettersson, A. (2013). Tribological characterization of environmentally adapted ester based fluids. Tribology International, vol. 36, no. 11, p. 815-820, Dol:10.1016/ S0301-679X(03)00098-7.

[18] Šauperl, I., Wimmer, A., Dimitrov, D., Zelenka, J., Pirker, G., Schnessl, E., Winter, H. (2018). LDM COMPACT - a highly efficient method for developing gas engines for use with low environmental impact non-natural gas. Strojniški vestnik Journal of Mechanical Engineering, vol. 64, no. 12, p. 743752, D0l:10.5545/sv-jme.2018.5344.

[19] Chen, Y., He, J., Wu, K., Zhao, Y., Wang, Z. (2018). Investigation of the energy regeneration and control strategy of a crane hoisting system. Strojniški vestnik - Journal of Mechanical Engineering, vol. 64, no. 3, p. 157-168, D0l:10.5545/svjme.2017.4717.

[20] Simič, R., Kalin, M., Kovač, J., Jakša, G. (2016). Adsorption of alcohols and fatty acids onto hydrogenated (a-C:H) DLC coatings. Applied Surface Science, vol. 363, p. 466-476, DOI:10.1016/j.apsusc.2015.12.066.

[21] Sin, J.R., Suñer, S., Neville, A., Emami, N. (2014). Fretting corrosion of hafnium in simulated body fluids. Tribology International, vol. 75, p. 10-15, D0l:10.1016/j. triboint.2014.03.003.

[22] Jost, H.P. (2009). The Presidential address. World Tribology Congress, Kyoto, Japan.

[23] Kandeva, M., Assenova, E., Daneva, M. (2009). Triboecology as a methodological center of modern science, $2^{\text {nd }}$ ECOTRIB Proceedings, Pisa.

[24] Bartz, W.J. (1998). Lubricants and the environment. Tribology International, vol. 31, no. 1-3, p. 35-47, D0l:10.1016/S0301679X(98)00006-1.

[25] TOTAL, Biodegradable lubricants for industry. (2015). From: http://www.lubricants.total.com/industry/business-sectors/ biodegradable-lubricants.html, accessed on 2019-09-16.

[26] Fuchs, Biodegradable (2015). From: http://www. fuchslubricants.com/hydraulic-oils-biodegradable, accessed on 2019-09-16.

[27] EC Council Directive 75/439/EEC on the disposal of waste oils (1975). Official Journal of the European Communities, Brussels.

[28] Waste Oils (2015). From: http://ec.europa.eu/environment/ waste/oil_index.htm, accessed on 2019-09-16.

[29] Bhushan, B. (2009). Biomimetics: lessons from nature - an overview. Philosophical Transactions of the Royal Society A, vol. 367, p. 1445-1486, D0l:10.1098/rsta.2009.0011.

[30] Fratzl, P. (2007). Biomimetic materials research: what can we really learn from nature's structural materials?. Journal of the Royal Society Interface, vol. 4, p. 637-642, D0l:10.1098/ rsif.2007.0218.

[31] Nosonovsky, M. (2007). Multiscale roughness and stability of superhydrophobic biomimetic interfaces. Langmuir, vol. 23, no. 6, p. 3157-3161, D0I:10.1021/la062301d.

[32] Robertson, J. (2003). Requirements of ultrathin carbon coatings for magnetic storage technology. Tribology 
International, vol. 36 , no. 4-6, p. 405-415, D0l:10.1016/ S0301-679X(02)00216-5.

[33] Sánchez-López, J. C., Erdemir, A., Donnet, C., Rojas, T.C. (2003). Friction-induced structural transformations of diamondlike carbon coatings under various atmospheres. Surface and Coatings Technology, vol. 163-164, p. 444-450, Dol:10.1016/S0257-8972(02)00641-2.

[34] Schulz, H., Leonhardt, M., Scheibe, H.-J., Schultrich, B. (2005). Ultra hydrophobic wetting behaviour of amorphous carbon films. Surface and Coatings Technology, vol. 200, no. 1-4, p. 1123-1126, D0I:10.1016/j.surfcoat.2005.02.019.

[35] Roy, R.K., Choi, H.-W., Park, S.-J., Lee, K.-R. (2007). Surface energy of the plasma treated $\mathrm{Si}$ incorporated diamond-like carbon films. Diamond and Related Materials, vol. 16, no. 9, p. 1732-1738, D0I:10.1016/j.diamond.2007.06.002.

[36] Grischke, M., Hieke, A., Morgenweck, F., Dimigen, H. (1998). Variation of the wettability of DLC-coatings by network modification using silicon and oxygen. Diamond and Related Materials, vol. 7, no. 2-5 p. 454-458, DOl:10.1016/S09259635(97)00237-9.

[37] Kalin, M., Vižintin, J., Barriga, J., Vercammen, K., Van Acker, K., Arnšek, A. (2004). The effect of doping elements and oil additives on the tribological performance of boundarylubricated DLC/DLC contacts. Tribology Letters, vol. 17, no. 4, p. 679-688, DOl:10.1007/s11249-004-8073-1.

[38] Neville, A., Morina, A., Haque, T., Voong, M. (2007). Compatibility between tribological surfaces and lubricant additives-How friction and wear reduction can be controlled by surface/lube synergies. Tribology International, vol. 40, no. 10-12, p. 1680-1695, D0l:10.1016/j.triboint.2007.01.019.

[39] Kalin, M., Vižintin, J., Vercammen, K., Barriga, J., Arnšek, A. (2006). The lubrication of DLC coatings with mineral and biodegradable oils having different polar and saturation characteristics. Surface and Coatings Technology, vol. 200, no. 14-15, p. 4515-4522, D0I:10.1016/j.surfcoat.2005.03.016.

[40] Kalin, M., Vižintin, J. (2005). The tribological performance of DLC-coated gears lubricated with biodegradable oil in various pinion/gear material combinations. Wear, vol. 259, no. 7-12, p. 1270-1280, D0l:10.1016/j.wear.2005.02.028.

[41] Barriga, J., Kalin, M., Van Acker, K., Vercammen, K., Ortega, A., Leiaristi, L. (2006). Tribological performance of titanium doped and pure DLC coatings combined with a synthetic bio-lubricant. Wear, vol. 261, no. 1, p. 9-14, D0l:10.1016/j. wear.2005.09.004.

[42] Kalin, M., Majdič, F., Vižintin, J., Pezdirnik, J., Velkavrh, I. (2008). Analyses of the long-term performance and tribological behavior of an axial piston pump using diamondlike-carboncoated piston shoes and biodegradable oil. Journal of Tribology, vol. 130, no. 1, Dol:10.1115/1.2805442.

[43] Kalin, M., Vižintin, J. (2006). Differences in the tribological mechanisms when using non-doped, metal-doped (Ti, WC), and non-metal-doped (Si) diamond-like carbon against steel under boundary lubrication, with and without oil additives. Thin Solid Films, vol. 515, no. 4, p. 2734-2747, D0I:10.1016/j. tsf.2006.03.034.

[44] Haque, T., Morina, A., Neville, A., Kapadia, R., Arrowsmith, S. (2007). Non-ferrous coating/lubricant interactions in tribological contacts: assessment of tribofilms.
Tribology International, vol. 40, no. 10-12, p. 1603-1612, D0I:10.1016/j.triboint.2007.01.023.

[45] Kalin, M., Roman, E., Vižintin, J. (2007). The effect of temperature on the tribological mechanisms and reactivity of hydrogenated, amorphous diamond-like carbon coatings under oil-lubricated conditions. Thin Solid Films, vol. 515, no. 7-8, p. 3644-3652, D0l:10.1016/j.tsf.2006.09.049.

[46] De Barros'Bouchet, M.I., Martin, J.M., Le-Mogne, T., Vacher, B. (2005). Boundary lubrication mechanisms of carbon coatings by MoDTC and ZDDP additives. Tribology International, vol. 38, no. 3, p. 257-264, D0l:10.1016/j.triboint.2004.08.009.

[47] Haque, T., Morina, A., Neville, A., Kapadia, R., Arrowsmith, S. (2007). Study of the ZDDP antiwear tribofilm formed on the DLC coating using AFM and XPS techniques. Journal of ASTM International, vol. 4, no. 7, p. 1-11, Dol:10.1520/JAI100937.

[48] Topolovec-Miklozic, K., Lockwood, F., Spikes, H. (2008). Behaviour of boundary lubricating additives on DLC coatings. Wear, vol. 265, no. 11-12, p. 1893-1901, D0l:10.1016/j. wear.2008.04.051.

[49] Equey, S., Roos, S., Mueller, U., Hauert, R., Spencer, N.D., Crockett, R. (2008). Tribofilm formation from ZnDTP on diamond-like carbon. Wear, vol. 264, no. 3-4, p. 316-321, Dol:10.1016/j.wear.2007.03.012.

[50] Kalin, M., Roman, E., Ožbolt, L., Vižintin, J. (2010). Metaldoped (Ti, WC) diamond-like carbon coatings: reactions with extreme-pressure oil additives under tribological and static conditions. Thin Solid Films, vol. 518, no. 15, p. 4336-4344, D0I:10.1016/j.tsf.2010.02.066.

[51] Yang, L., Neville, A., Brown, A., Ransom, P., Morina, A. (2015). Effect of lubricant additives on the WDLC coating structure when tested in boundary lubrication regime. Tribology Letters, vol. 57, no. 14, Dol:10.1007/s11249-015-0464-y.

[52] Durham, J., Kidson, A. (2014). The effects of low sulfated ash, phosphorus and sulfur oils on camshaft/tappet tribocouples with various diamond-like-carbon coated tappets in motored and fired engines. Lubrication Science, vol. 26, no. 6, p. 411427, D0I:10.1002/Is.1251.

[53] Oblak, E., Kalin, M. (2015). Relationship between the nanoscale topographical and mechanical properties of tribochemical films on DLC coatings and their macroscopic friction behavior. Tribology Letters, vol. 59, no. 49, p. 1-16, DOI:10.1007/s11249-015-0575-5.

[54] Kalin, M., Oblak, E., Akbari, S. (2016). Evolution of the nanoscale mechanical properties of tribofilms formed from lowand high-SAPS oils and ZDDP on DLC coatings and steel. Tribology International, vol. 96, p. 43-56, D0l:10.1016/j. triboint.2015.12.013.

[55] Simič, R., Kalin, M. (2013). Adsorption mechanisms for fatty acids on DLC and steel studied by AFM and tribological experiments. Applied Surface Science, vol. 283, p. 460-470, D0I:10.1016/J.apsusc.2013.06.131.

[56] Simič, R., Kalin, M. (2013). Comparison of alcohol and fatty acid adsorption on hydrogenated DLC coatings studied by AFM and tribological tests. Strojniški vestnik - Journal of Mechanical Engineering, vol. 59, no. 12, p. 707-718, DOI:10.5545/sv-jme.2013.1228.

[57] Kalin, M., Simič, R. (2013). Atomic force microscopy and tribology study of the adsorption of alcohols on diamond-like 
carbon coatings and steel. Applied Surface Science, vol. 271, p. 317-328, DOI:10.1016/j.apsusc.2013.01.192.

[58] Simič, R., Kalin, M., Hirayama, T., Korelis, P., Geue, T. (2014). Fatty acid adsorption on several DLC coatings studied by neutron reflectometry. Tribology Letters, vol. 53, no. 1, p. 199206, DOI:10.1007/s11249-013-0257-0.

[59] Kalin, M., Simič, R., Hirayama, T., Geue, T., Korelis, P. (2014). Neutron-reflectometry study of alcohol adsorption on various DLC coatings. Applied Surface Science, vol. 288, p. 405-410, DOI:10.1016/j.apsusc.2013.10.047.

[60] Loehlé, S., Matta, C., Minfray, C., Le Mogne, T., lovine, R., Obara, Y., Miyamoto, A., Martin, J.M. (2016). Mixed lubrication of steel by $\mathrm{C} 18$ fatty acids revisited. Part II: Influence of some key parameters. Tribology International, vol. 94, p. 207-216, D0I:10.1016/j.triboint.2015.08.036.

[61] Fontaine, J., Donnet, C., Grill, A., Le Mogne, T. (2001). Tribochemistry between hydrogen and diamond-like carbon films. Surface and Coatings Technology, vol. 146-147, p. 286291, DOI:10.1016/S0257-8972(01)01398-6.

[62] Donnet, C., Fontaine, J., Grill, A., Le Mogne, T. (2000). The role of hydrogen on the friction mechanism of diamond-like carbon films. Tribology Letters, vol. 9, no. 3-4, p. 137-142, DOI:10.1023/A:1018800719806.

[63] Erdemir, A. (2001). The role of hydrogen in tribological properties of diamond-like carbon films. Surface and Coatings Technology, vol. 146-147, p. 292-298, D0l:10.1016/S02578972(01)01417-7.

[64] Velkavrh, I., Kalin, M. (2012). Comparison of the effects of the lubricant-molecule chain length and the viscosity on the friction and wear of diamond-like-carbon coatings and steel. Tribology International, vol. 50, p. 57-65, D0l:10.1016/j. triboint.2012.01.008.

[65] Maugis, D. (2001). Adhesion of Solids: Mechanical Espects. Modern Tribology Handbook, Volume One, (Bhushan, B. ed.), 163-203, CRC Press, Boca Raton.

[66] Roberts, E.W. (1990). Thin solid lubricant films in space. Tribology International, vol. 23, no. 2, p. 95-104, D0I:10.1016/0301-679X(90)90042-N.

[67] Singer, I.L. (1992). Solid lubrication processes. Fundamentals of Friction: Macroscopic and Microscopic Processes, (Singer, I.L., Pollock, H.M., eds.), Kluwer Academic Publishers, Dordrecht, p. 237-261, D0I:10.1007/978-94-011-2811-7_13.

[68] Martin, J.M., Donnet, C., Le Mogne, Th., Epicier, Th. (1993). Superlubricity of molybdenum disulphide. Physical Review B, vol. 48, no. 14, p. 10583-10586, D0l:10.1103/ PhysRevB.48.10583.

[69] Singer, I.L. (1996). Mechanics and chemistry of solids in sliding contact. Langmuir, vol. 12, no. 19, p. 4486-4491, DOl:10.1021/la951056n.

[70] Rapoport, L., Bilik, Y., Feldman, Y., Homyonfer, M., Cohen, S. R., Tenne, R. (1997). Hollow nanoparticles of $\mathrm{WS}_{2}$ as potential solid-state lubricants. Nature, vol. 387, p. 791-793, DOI:10.1038/42910.

[71] Rapoport, L., Feldman, Y., Homyonfer, M., Cohen, H., Sloan, J., Hutchison, J.L., Tenne, R. (1999). Inorganic fullerenelike material as additives to lubricants: structure-function relationship. Wear, vol. 225-229, p. 975-982, D0l:10.1016/ S0043-1648(99)00040-X.
[72] Greenberg, R., Halperin, G., Etsion, I., Tenne, R. (2004). The effect of $W_{2}$ nanoparticles on friction reduction in various lubrication regimes. Tribology Letters, vol. 17, no. 2, p. 179186, D0I:10.1023/B:TRIL.0000032443.95697.1d.

[73] Joly-Pottuz, L., Dassenoy, F., Belin, M., Vacher, B., Martin, J.M., Fleischer, N. (2005). Ultralow-friction and wear properties of IF-WS 2 under boundary lubrication. Tribology Letters, vol. 18, no. 4, p. 477-485, DOI:10.1007/s11249-005-3607-8.

[74] Moshkovith, A., Perfiliev, V., Verdyan, A., Lapsker, I., PopovitzBiro, R., Tenne, R., Rapoport, L. (2007). Sedimentation of IF-WS $\mathrm{S}_{2}$ aggregates and a reproducibility of the tribological data. Tribology International, vol. 40, no. 1, p. 117-124, D0l:10.1016/j.triboint.2006.02.067.

[75] Rosentsveig, R., Gorodnev, A., Feuerstein, N., Friedman, H., Zak, A., Fleischer, N., Tannous, J., Dassenoy, F., Tenne, R. (2009). Fullerene-like $\mathrm{MoS}_{2}$ nanoparticles and their tribological behavior. Tribology Letters, vol. 36, no. 2, p. 175182, D0I:10.1007/s11249-009-9472-0.

[76] Tannous, J., Dassenoy, F., Lahouij, I., Le Mogne, T., Vacher, B., Bruhács, A., Tremel, W. (2011). Understanding the tribochemical mechanisms of IF-MoS 2 nanoparticles under boundary lubrication. Tribology Letters, vol. 41, no. 1, p. 5564, D0I:10.1007/s11249-010-9678-1.

[77] Kalin, M., Kogovšek, J., Remškar, M. (2012). Mechanisms and improvements in the friction and wear behavior using $\mathrm{MoS}_{2}$ nanotubes as potential oil additives. Wear, vol. 280-281, p. 36-45, D0l:10.1016/J.wear.2012.01.011.

[78] Kogovšek, J., Remškar, M., Mrzel, A., Kalin, M. (2012). Influence of surface roughness and running-in on the lubrication of steel surfaces with oil containing $\mathrm{MoS}_{2}$ nanotubes in all lubrication regimes. Tribology International, vol. 61, p. 40-47, D0l:10.1016/j.triboint.2012.12.003.

[79] Salmeron, M., Somorjai, G.A., Wold, A., Chianelli, R.R., Liang, K.S. (1982). The adsorption and binding of thiophene, butene and $\mathrm{H} 2 \mathrm{~S}$ on the basal plane of $\mathrm{MoS}_{2}$ single crystals. Chemical Physics Letters, vol. 90, no. 2, p. 105-107, Dol:10.1016/0009. 2614(82)83620-8.

[80] Berman, D., Erdemir, A., Sumant, A.V. (2013). Few layer graphene to reduce wear and friction on sliding steel surfaces. Carbon, vol. 54, p. 454-459, D0l:10.1016/j. carbon.2012.11.061.

[81] Song, H.-J., Li, N. (2011). Frictional behavior of oxide graphene nanosheets as water-base lubricant additive. Applied Physics A, vol. 105, no. 4, p. 827-832, Dol:10.1007/s00339-0116636-1.

[82] Lin, J., Wang, L., Chen, G. (2011). Modification of graphene platelets and their tribological properties as a lubricant additive. Tribology Letters, vol. 41, no. 1, p. 209-215, D0l:10.1007/s11249-010-9702-5.

[83] Choudhary, S., Mungsea, H.P., Khatri, O.P. (2012). Dispersion of alkylated graphene in organic solvents and its potential for lubrication applications. Journal of Materials Chemistry, no. 39, DOI:10.1039/C2JM34741E.

[84] Kogovšek, J., Kalin, M. (2019). Lubrication performance of graphene-containing oil on steel and DLC-coated surfaces. Tribology International, vol. 138, p. 59-67, D0l:10.1016/j. triboint.2019.05.026. 
[85] Kalin, M., Velkavrh, I., Vižintin, J. (2009). The Stribeck curve and lubrication design for non-fully wetted surfaces. Wear, vol. 267, no. 5-8, p. 1232-1240, Dol:10.1016/j.wear.2008.12.072.

[86] Kalin, M., Polajnar, M. (2013). The effect of wetting and surface energy on the friction and slip in oil-lubricated contacts. Tribology Letters, vol. 52, no. 2, p. 185-194, D0I:10.1007/s11249-013-0194-y.

[87] Polajnar, M., Kalin, M. (2015). Effect of the slide-to-roll ratio and the contact kinematics on the elastohydrodynamic friction in diamond-like-carbon contacts with different wetting behaviours. Tribology Letters, vol. 60 , no. 8, p. 1-10, D0I:10.1007/s11249-015-0593-3.

[88] Jahanmir, S., Hunsberger, A.Z., Heshmnat, H. (2011). Load capacity and durability of H-DLC coated hydrodynamic thrust bearings. Journal of Tribology, vol. 133, no. 3, DOl:10.1115/1.4003997.

[89] Evans, R.D., Cogdell, J.D., Richter, G.A., Doll, G.L. (2009). Traction of lubricated rolling contacts between thin-film coatings and steel. Tribology Transactions, vol. 52, no. 1, p. 106-113, DOI:10.1080/10402000802180144.

[90] Vinogradova, O.I. (1999). Slippage of water over hydrophobic surfaces. International Journal of Mineral Processing, vol. 56, no. 1-4, p. 31-60, D0l:10.1016/S0301-7516(98)00041-6.

[91] Spikes, H., Granick, S. (2003). Equation for slip of simple liquids at smooth solid surfaces. Langmuir, vol. 19, no. 12, p. 5065-5071, D0I:10.1021/la034123j.

[92] Hild, W., Optiz, A., Schaefer, J.A., Scherge, M. (2003). The effect of wetting on the microhydrodinamics of surfaces lubricated with water and oil. Wear, vol. 254, no. 9, p. 871875, DOI:10.1016/S0043-1648(03)00238-2.

[93] Choo, H., Spikes, H.A., Ratoi, M., Glovnea, R., Forrest, A. (2007). Friction reduction in low-load hydrodynamic lubrication with a hydrophobic surface. Tribology International, vol. 40, no. 2, p. 154-159, D0l:10.1016/j.triboint.2005.09.006.

[94] Maali, A., Bhushan, B. (2008). Nanorheology and boundary slip in confined liquids using atomic force microscopy. Journal of Physics: Condensed Matter, vol. 20, no. 31, p. 1-11, DOl:10.1088/0953-8984/20/31/315201.

[95] Kus, M., Kalin, M. (2019). Influence of additives and their molecular structure on the static and dynamic wetting of oil on steel at room temperature. Applied Surface Science, vol. 490, p. 420-429, DOI:10.1016/j.apsusc.2019.06.111.

[96] Welton, T. (1999). Room-temperature ionic liquids. Solvents for synthesis and catalysis. Chemical Reviews, vol. 99, no. 8, p. 2071-2084, DOI:10.1021/cr980032t.

[97] Keskin, S., Kayrak-Talay, D., Akman, U., Hortaçsu, Ö. (2007). A review of ionic liquids towards supercritical fluid applications. The Journal of Supercritical Fluids, vol. 43, no. 1, p. 150-180, D0I:10.1016/j.supflu.2007.05.013.

[98] Abrusci, C., Palomar, J., Pablos, J.L., Rodriguez, F., Catalinac, F. (2011). Efficient biodegradation of common ionic liquids by Sphingomonas paucimobilis bacterium. Green Chemistry, vol. 13, no. 3, p. 709-717, DOl:10.1039/COGC00766H.

[99] Blanco, D., Oulego, P., Ramos, D., Fernández, B., Cuetos, M. (2017). Model-free kinetics applied to evaluate the long-term thermal stability of three $\left[\mathrm{NTf}_{2}\right]$ anion-based ionic liquids. Thermochimica Acta, vol. 656, p. 70-84, D0l:10.1016/j. tca.2017.08.002.
[100]Tomizawa, H., Fischer, T.E. (1987). Friction and wear of silicon nitride and silicon carbide in water: Hydrodynamic lubrication at low sliding speed obtained by tribochemical wear. ASLE Transactions, vol. 30, no. 1, p. 41-46, DOI:10.1080/05698198708981728.

[101]Jordi, L., Iliev, C., Fischer, T.E. (2004). Lubrication of silicon nitride and silicon carbide by water: Running in, wear and operation of sliding bearings. Tribology Letters, vol. 17. no. 3, p. 367-376, DOI:10.1023/B:TRIL.0000044485.77019.fb.

[102]Chen, M., Kato, K., Adachi, K. (2002). The comparisons of sliding speed and normal load effect on friction coefficients of self-mated Si3N4 and SiC under water lubrication. Tribology International, vol. 35, no. 3, p. 129-135, Dol:10.1016/S0301679X(01)00105-0.

[103]Jahanmir, S., Fisher, T.E. (1989). Friction and wear of slilicon nitride lubricated by humid air, water, hexadecane and hexadecane +0.5 percent stearic acid. Tribology Transactions, vol. 31, no. 1, p. 32-43, D0l:10.1080/10402008808981795.

[104]Kalin, M., Novak, S., Vižintin, J. (2003). Wear and friction behaviour of alumina ceramics in aqueous solutions with different pH. Wear, vol. 254, no. 11, p. 1141-1146, DOI:10.1016/S0043-1648(03)00326-0.

[105]Novak, S., Drazic, G., Kalin, M. (2005). Structural changes in $\mathrm{ZrO}_{2}$ ceramics during sliding under various environments. Wear, vol. 259, no. 1-6, p. 562-568, D0l:10.1016/j. wear.2004.12.001.

[106]Kalin, M., Dražič, G., Novak, S., Vižintin, J. (2006). Wear mechanisms associated with the lubrication of zirconia ceramics in various aqueous solutions. Journal of the European Ceramic Society, vol. 26, no. 3, p. 223-232, D0I:10.1016/j.jeurceramsoc.2004.10.026.

[107]Kalin, M., Novak, S., Vižintin, J. (2006). Surface charge as a new concept for boundary lubrication of ceramics with water. Journal of Physics D: Applied Physics, vol. 39, no. 15, p. 31383149, DOI:10.1088/0022-3727/39/15/S03.

[108]Erdemir, A. (2004). Diamond-like carbon films. Vižintin, J., Kalin, M., Dohda, K., Jahanmir, S. (eds.), Tribology of Mechanical Systems: A Guide to Present and Future Technologies. ASME Press, New York. p. 139-156, DOI:10.1115/1.802094.ch8.

[109]Sato, T., Besshi, T., Sato, D., Tsutsui, I. (2001). Effect of water based lubricants on wear of coated material. Wear, vol. 249, no. 1-2, p. 50-55, Dol:10.1016/S0043-1648(01)00522-1.

[110]Kano, M., Martin, J.M., Bouchet, M.I.D.B. (2017). Green superlubrication by hydrogen-free amorphous carbon with human friendly lubricants. Sensors and Materials, vol. 29, no. 6, p. 771-784, DOI:10.18494/SAM.2017.1630.

[111]Uchidate, M., Liu, H., Iwabuchi, A., Yamamoto, K. (2007). Effects of water environment on tribological properties of DLC rubbed against stainless steel. Wear, vol. 263, no. 7-12, p. 1335-1340, D0I:10.1016/j.wear.2006.10.024.

[112] Yamamoto, K., Matsukado, K. (2006). Effect of hydrogenated DLC coating hardness on the tribological properties under water lubrication. Tribology International, vol. 39, no. 12, p. 1609-1614, D0l:10.1016/j.triboint.2006.01.004.

[113]Tokoro, M., Aiyama, Y., Masuko, M., Suzuki, A., Ito, H., Yamamoto, K. (2009). Improvement of tribological characteristics under water lubrication of DLC-coatings by 
surface polishing. Wear, vol. 267, no. 12, p. 2167-2172, D0l:10.1016/J.wear.2009.04.009.

[114]Ohana, T., Wu, X., Nakamura, T., Tanaka, A. (2007). Formation of lubrication film of diamond-like carbon films in water and air environments against stainless steel and Cr-plated balls. Diamond and Related Materials, vol. 16, no. 4-7, p. 13361339, DOl:10.1016/j.diamond.2007.01.036.

[115]Ohana, T., Suzuki, M., Nakamura, T., Tanaka, A., Koga, Y. (2004). Tribological properties of DLC films deposited on steel substrate with various surface roughness. Diamond and Related Materials, vol. 13, no. 11-12, p. 2211-2215, DOI:10.1016/j.diamond.2004.06.037.

[116] Tanaka, A., Suzuki, M., Ohana, T. (2004). Friction and wear of various DLC films in water and air environments. Tribology Letters, vol. 17, no. 4, p. 917-924, D0l:10.1007/s11249-0048100-2.

[117]Suzuki, M., Tanaka, A., Ohana, T., Zhang, W. (2004). Frictional behavior of DLC films in a water environment. Diamond and Related Materials, vol. 13, no. 4-8, p. 1464-1468, DOl:10.1016/j.diamond.2003.10.068.

[118]Majdič, F., Velkavrh, I., Kalin, M. (2013). Improving the performance of a proportional 4/3 water-hydraulic valve by using a diamond-like-carbon coating. Wear, vol. 297, no. 1-2, p. 1016-1024, D0l:10.1016/j.wear.2012.11.060.

[119]Strmčnik, E., Majdič, F., Kalin, M. (2019). Water-lubricated behaviour of AISI $440 \mathrm{C}$ stainless steel and a DLC coating for an orbital hydraulic motor application. Tribology International, vol. 131, p. 128-136, D0l:10.1016/j.triboint.2018.10.032.

[120]Strmčnik, E., Majdič, F., Kalin, M. (2019). Influence of a diamond-like carbon-coated mechanical part on the operation of an orbital hydraulic motor in water. Metals, vol. 9, no. 4, p. 466, DOl:10.3390/met9040466.

[121]GreenTRIBOS - European Network for Joint Doctoral-Level Training in Green Tribology Marie-Sklodowska-Curie actions: H2020-MSCA-ITN-2019 (2019). from http://www.greentribos. org, accessed on 2019-10-22. 